
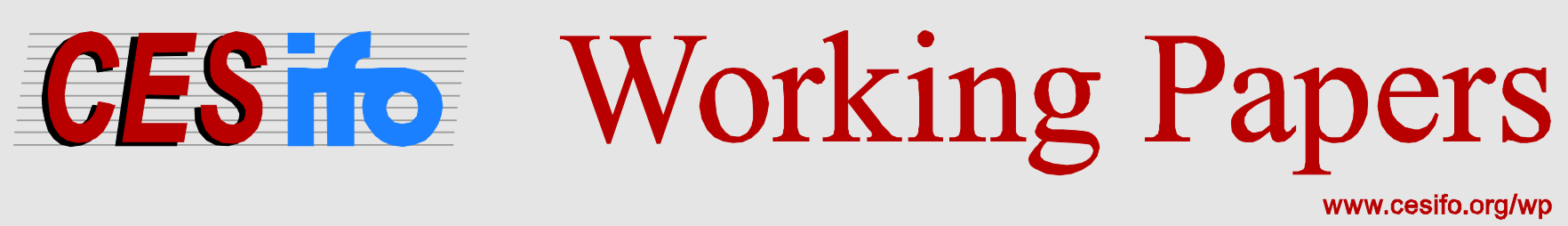

\title{
Identification and Estimation of the Environmental Kuznets Curve: Pairwise Differencing to Deal with Nonlinearity and Nonstationarity
}

\author{
Suphi Sen \\ Bertrand Melenberg \\ Herman Vollebergh
}

CESIFO WORKING PAPER NO. 5837

CATEGORY 10: ENERGY AND ClimATE ECONOMICS

MARCH 2016

An electronic version of the paper may be downloaded

- from the SSRN website:

- from the RePEc website:

- from the CESifo website:

wWw.SSRN.com

Www.RePEc.org

www.CESifo-group.org/wp 


\title{
Identification and Estimation of the Environmental Kuznets Curve: Pairwise Differencing to Deal with Nonlinearity and Nonstationarity
}

\begin{abstract}
We propose an estimation strategy that accounts for two major problems raised in the empirical literature testing for the prevalence of the inverted U-shaped relation between environmental degradation and economic activity, namely the Environmental Kuznets Curve (EKC) hypothesis. First, we use pairwise differencing to properly identify the income effect, and to make use of estimators that likely suffer less from heterogeneity, cross-sectional dependence, and other common factor problems. Second, we apply nonlinear-nonstationary parametric and non-parametric estimation techniques to estimate the pairwise differenced regressions, since panel unit root tests indicate that our income and emission series are integrated of order one. Our results for regional $\mathrm{CO}_{2}$ emissions systematically yield positive income effects while the estimated time effects do not compensate for these income effects sufficiently to generate an inverted U-shape for $\mathrm{CO}_{2}$ emissions.
\end{abstract}

JEL-Codes: C220, C330, O500, Q500.

Keywords: $\mathrm{CO}_{2}$ emissions, unit roots, nonlinearity, nonparametric estimation.

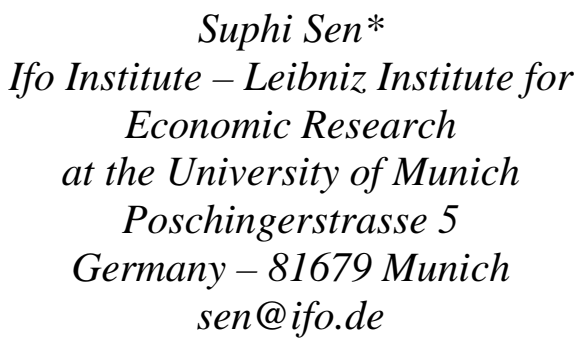

Bertrand Melenberg

CentER and Department of Econometrics

\& OR / Tilburg University

Tilburg / The Netherlands

b.melenberg@uvt.nl
Herman Vollebergh

Netherlands Environmental Assessment Agency, CentER \& Tilburg Sustainability Center / Tilburg University

The Netherlands herman.vollebergh@pbl.nl 


\section{Introduction}

The large literature estimating Environmental Kuznets Curve (EKC hereafter) postulates an inverted U-shaped relationship between environmental pollution and per capita gross domestic product (GDP). Environmental pollution is assumed to follow an increasing pattern up to a certain level of per capita income and once that level, which is called "turning point," is reached, pollution starts to decline. This so called EKC hypothesis has been tested in numerous empirical papers for many environmental indicators and (sub)samples of countries mostly in a panel setting following the seminal paper by Grossman and Krueger (1991). At the same time, this literature has also been severely criticized, for example, for applying unsatisfactory econometric techniques (see, for instance, Millimet et al., 2003; Stern, 2004; Wagner, 2008). Others like Vollebergh et al. (2009) have raised fundamental identification problems in this context because one may be concerned by the interaction between the main explanatory variable (income effect) and its controls (for example, time effects).

This paper proposes and applies a new estimation approach that controls for two of the major challenges that plague EKC estimation. First, a somewhat older and persistent issue is that per capita income and emission series might be non-stationary, and only if the series would be cointegrated, the estimations would properly take this non-stationarity into account (for example, De Bruyn et al. (1998)). Even contributions that control for this issue (see, for instance, Perman and Stern (2003)) have been criticized, however, because results are dependent on the type of unit root or cointegration tests chosen (see, for instance, Wagner (2008)). ${ }^{1}$ Moreover, as argued by Muller-Furstenberger and Wagner (2007) and formalized by Wagner and Hong (2015), a non-linear functional specification of a nonstationary exogenous variable requires an appropriate estimation technique in combination with an appropriate cointegration test for the hypothesized relation.

Second, and at a more fundamental level, the existing literature also suffers from nonrobustness due to the use of different econometric techniques (for example, Harbaugh et al. (2002)), the role of heterogeneity in panel based estimations (for example, Dijkgraaf and Vollebergh (2005)) and cross-section dependency (Wagner, 2008). Vollebergh et al. (2009) have noted that these issues in this reduced form setting are likely to be related to identification problems arising from the separation of a time related independent variable, in this case income, from control variables, like country and time effects in particular. They show that restrictions imposed on the controls are likely to seriously affect the shape of the estimated

\footnotetext{
${ }^{1}$ Wagner (2008) finds no longer significant evidence in favor of the EKC hypothesis if one properly accounts for cross-sectional dependence compared to cointegrated estimators that do not control for this dependency. Galeotti et al. (2009) criticize unit root and cointegration tests because they do not allow the order of integration to take a non-integer values. By applying fractional unit root and cointegration tests in a panel context which allows the order of integration to be non-integer values, they find mixed results. However, their method does not account of cross sectional dependency nor does their estimation strategy take account of nonlinear terms of GDP per capita.
} 
income-emission relationship. As a solution to this fundamental problem they propose to identify the income effect under the assumption that for each region there is at least one other region having the same time effect. Taking pairwise differences then eliminates the common time effect and allows a fully nonparametric estimation of the income effects. When applying this pairwise differencing strategy, however, Vollebergh et al. (2009) assume the variables of interest to be stationary, and therefore, their approach is subject to the previous criticism.

The aim of this paper is to deal with both criticisms at the same time. Our starting point is the new identification approach proposed by Vollebergh et al. (2009) that yields an income effect consistent with important theoretical specifications of the long run mechanisms that drive economic growth models (for example, Brock and Taylor (2005)). Their identification approach, however, assumes that a pair of countries or regions have a common time effect while they select country pairs based on the best fitting country. In this paper, we do not assume the existence of a common time effect. Instead, we simply define the income effect of a country or region, relative to another country or region, to be what remains (as function of income) after taking differences which eliminates common time effects. ${ }^{2}$ So what remains is the difference of the two income effects of the two paired countries or regions (with respect to each other). In this way, the two income effects are identified and can be estimated both parametrically and fully non-parametrically without imposing any functional form restriction. In addition, the common time effects, which are differenced out, are allowed to be fully flexible as well. Each country or region can be coupled with any other country or region, generating case specific decompositions of total emissions into an income and a time effect (and a residual idiosyncratic effect) relative to the coupled region. In other words, both effects exist only relative to another country or region. ${ }^{3}$

In line with the first criticism, we also observe that our series are sensitive to nonstationarity and require proper estimation techniques in the face of those problems. However, we also aim to remain as flexible as possible in applying different parametric and non-parametric estimation techniques in order to avoid potential misspecification. Our parametric benchmark estimation strategy follows "Efficient nonstationary nonlinear least squares" (EN-NLS) as suggested by Chang et al. (2001). Although this estimation approach allows for a wide variety of nonlinear functions, our focus here is on polynomials (one for each income effect). The order of the polynomial in our approach is empirically based and not assumed right from the start. We

\footnotetext{
${ }^{2}$ Without a common time effect, a country or region would have its own time effect. However, a countryor region-specific time effect, without further restrictions, can be made so flexible that it captures all variation in the dependent variable, leaving no room for an income effect.

${ }^{3}$ Our pairwise differencing strategy eliminates not only the effects that are common to all cross-sectional units, but also all pair specific common effects. Therefore this strategy also accounts for cross-sectional dependence problems raised for the panel estimations in the EKC literature. In the current paper we allow for full heterogeneity in the income effects and provide separate regressions for each pair. We leave improving the efficiency of our estimators by taking into account the possible correlations between different pairs to future research.
} 
test the underlying cointegration assumption, using residual based nonlinear cointegration tests developed by Wagner (2012) and Wagner and Hong (2015). Furthermore, to select pairs and to validate the parametric estimates we also apply a non-parametric approach. Here we follow Schienle (2013) who recently developed an estimator for non-parametric non-stationary regressions with many covariates and which is suitable for our case. ${ }^{4}$

Pairwise differencing can be applied to any country or region together with a paired country or region. In this study we explore the EKC hypothesis by focusing on large world regions (like in the context of the Intergovernmental Panel on Climate Change scenarios). We present the outcomes only for two regions in the main text, namely, "Western Offshoots" (consisting of the Australia, Canada, New Zealand, and the United States), representing a developed region, and China, representing a developing region. The outcomes for the other (seven) regions are reported in the appendix. ${ }^{5}$ Environmental quality is proxied by $\mathrm{CO}_{2}$ emission per capita (Boden et al., 2013) and economic activity by GDP per capita (the Maddison-Project, 2013 version). ${ }^{6}$ We use data over the period 1950 to 2010.

We find, first, that the second generation panel unit root tests (applied to the panel including all nine regions) clearly indicate nonstationarity in the form of unit roots in both $\mathrm{CO}_{2}$ emission per capita and GDP per capita. Second, using the nonparametric estimator of Schienle (2013), we pair Western Offshoots to Western Europe (i.e., the former EU) and we pair China to Latin America. Third, both our parametric and non-parametric estimations, which allow for nonlinearity and nonstationarity, suggest no evidence for a slowdown in the income effects of both China relative to Latin America and Western Offshoots relative to Western Europe. More important, however, is that the calibrated time effect of China is clearly increasing too, while the negative time effects of Western Offshoots do not compensate for the corresponding positive income effects. Hence, we find no evidence supporting the EKC hypothesis for our investigated pairs, neither for the income effect, nor for the joint effect of both income and time.

The remainder of this paper is organized as follows. In the next section we discuss our identification strategy. In Section 3 we present our dataset and we investigate the stationarity properties of our data. Section 4 then describes the estimation strategies. In section 5, estimation results, focusing on China and Western Offshoots, are provided. Section 6 concludes.

\footnotetext{
${ }^{4}$ For the univariate case some studies exist on non-parametric non-stationary regressions (such as, for example, Wang and Phillips (2009) and Karlsen et al. (2007)). However, we focus on the special case where the two-dimensional nonstationarity in the GDP per capita levels of the paired regions turn out to be as nonstationary as in the univariate GDP per capita levels. In this special case, Schienle's estimator becomes the Smooth Backfitting Estimator; see Schienle (2013) for further details.

${ }^{5}$ The underlying data consists of a balanced panel from nine regions, where the regional division is geographically based and covers the whole world with only a few small country exceptions, see also Melenberg et al., 2011.

${ }^{6}$ See http://www.ggdc.net/maddison/maddison-project/home.htm. See also Maddison (2009).
} 


\section{Identification Strategy}

The general econometric model behind the empirical literature investigating the EKC hypothesis is as follows:

$$
y_{i t}=f\left(x_{i t}, i\right)+\lambda(i, t)+\varepsilon_{i t}
$$

where $i$ stands for the cross-sectional units, such as countries or regions, and $t$ represents time. The emissions, denoted with $y_{i t}$, is driven by two effects. The first one is the so called income

effect which is denoted with $f$, and which is a function of $x_{i t}$, i.e., GDP per capita. Secondly, $\lambda$ stands for the time effect. Finally, $\varepsilon_{i t}$ stands for the idiosyncratic error term. In this very general model, both income and time effect can also be a function of some cross-section specific effects. The functional form (1) can be motivated by the so-called IPAT-equation (see, for example, Chertow, 2000), i.e., $I=P \times A \times T$, where $I$ stands for the impact (in our case of carbon dioxide emission), $P$ stands for population, $A$ stands for affluence, and $T$ stands for technology. In per capita- and $\log$-terms we get $\log (I / P)=\log (A)+\log (T)$. Translated into equation (1), we model $y=\log (I / P)$ as a function $f$ of GDP per capita, representing $\log (A)$, plus a function $\lambda$ of time, representing $\log (T)$. Both $f$ and $\lambda$ are allowed to be cross section unit-specific. Adding the error term $\epsilon_{i t}$ completes specification (1).

In order to identify (and estimate) the hypothesized relationship between emission and income, we apply as identification strategy "pairwise differencing." This strategy does not impose any additional functional form restrictions (on top of equation (1)). Instead, it interprets what can be estimated, using equation (1), without additional functional form restrictions, after taking differences of $y_{i t}$ and $y_{k t}$ (for each $t$ ) of two different regions $i$ and $k$. Formally, consider two regions $i$ and $k$ collected in $c=\{i, k\}$. Then we define $f_{c}\left(x_{i t}, i\right)$ and $f_{c}\left(x_{k t}, k\right)$, the region-specific income effects of regions $i$ and $k$, respectively, given the set of regions $c$ as follows

$$
y_{j t}=f_{c}\left(x_{j t}, j\right)+\lambda_{c}(t)+\varepsilon_{c, j t}, j \in\{i, k\},
$$

where $\lambda_{c}(t)$ represents the common time effect, and where $\varepsilon_{c, j t}, j \in\{i, k\}$, are the regionspecific idiosyncratic error terms. Applying pairwise differencing to (2) with $j=i$ and $j=k$ leads to the following equation:

$$
y_{i t}-y_{k t}=f_{c}\left(x_{i t}, i\right)-f_{c}\left(x_{k t}, k\right)+\varepsilon_{c, i t}-\varepsilon_{c, k t} .
$$

Assuming (for example) $E\left(\varepsilon_{c, i t}-\varepsilon_{c, k t} \mid x_{i t}, x_{k t}\right)=0$, both $f_{c}(\cdot, i)$ and $f_{c}(\cdot, k)$ are identified (up to a constant), without imposing additional functional form restrictions. ${ }^{7}$ Moreover, because $\lambda_{c}(t)$ is differenced out, it can be any function of $t$.

We could generalize $c=\{i, k\}$ to $c=\left\{i,\left(k_{1}, \cdots, k_{T}\right)\right\}$, where $k_{t}$ is the coupled region at

\footnotetext{
${ }^{7}$ The assumption $E\left(\varepsilon_{c, i t}-\varepsilon_{c, k t} \mid x_{i t}, x_{k t}\right)=0$ identifies $h_{c}\left(x_{i t}, x_{k t}\right)=E\left(y_{i t}-y_{k t} \mid x_{i t}, x_{k t}\right)$. Then $\int h_{c}(\cdot, x) d \mu(x)=f_{c}(\cdot, i)+c$, for some constant $c$, where $\mu$ is some probability measure, satisfying $\int d \mu(x)=1$.
} 
time $t$, with $t \in\{1, \cdots, T\}$. In equation (3), applying to period $t$ we then have to replace $k$ by $k_{t}$. However, we leave this generalization to future research, assuming in this paper $k_{t}=k$ for all $t$.

The assumption of a common time effect $\left(\lambda_{c}(t)\right.$, for $\left.c=\{i, k\}\right)$ (or its generalization to $\left.c=\left\{i,\left(k_{1}, \cdots, k_{T}\right)\right\}\right)$ is a minimum requirement for being able to identify a nonzero income effect $f$. Without a common time effect, and without other constraints, the region-specific time effect $\lambda(i, t)$ can be made so flexible to capture all variation in the dependent variable (namely, by setting $\lambda(i, t)=y_{i t}$ ), leaving no room for a nonzero income effect.

A different coupling, represented by $c^{\prime} \neq c$, typically will generate a different income effect $f_{c^{\prime}}(\cdot, i) \neq f_{c}(\cdot, i)$ and a different time effect $\lambda_{c^{\prime}}(\cdot) \neq \lambda_{c}(\cdot)$. This shows that a region's income effect is only identified relative to another region, as given by the set $c$.

The next step is the estimation of (3). However, the appropriate estimation technique depends on the characteristics of the data, which we therefore consider first.

\section{Description and Properties of the Data}

Our underlying dataset is a balanced panel for all countries, covering the period between 1950 and 2010. $\mathrm{CO}_{2}$ emission data consist of the sum of emissions from gas, liquid and solid fuels (based on consumption figures), and from gas flaring and cement production (see Boden et al. (2013). For each type of fuel, data on annual $\mathrm{CO}_{2}$ emissions result from three aspects: the amount of fuel consumed, the fraction of the fuel that becomes oxidized, and a factor for the carbon content of the fuel. The fuel types incorporated in the calculations are coal, other solid fuels, crude oil, petroleum products, and natural gas. Total energy use and emissions per country are corrected for exports and imports of fuels, as well as for stock changes, international marine bunkers, and non-energy use of fuels, such as chemical feedstock. The estimation of the amounts of $\mathrm{CO}_{2}$ released through gas flaring are based on the UNSTAT database, supplemented by estimations from DOE/EIA. The estimations of the amounts of $\mathrm{CO}_{2}$ released from cement manufacturing are based on figures indicating the quantity of manufactured cement, the average calcium oxide content per unit of cement, and a factor to convert the calcium oxide content into $\mathrm{CO}_{2}$ equivalents. Data on GDP per capita is taken from the Maddison-Project, 2013 version. ${ }^{8}$ All figures are expressed in 1990 International Geary-Khamis dollars, using purchasing power parities.

We aggregate data on a country by country basis into nine regions: India, China, "Other Asia", Western Europe, Eastern Europe, Former USSR, "Western Offshoots", Africa, and Latin America. In contrast to the division into regions by the Intergovernmental Panel on Climate

\footnotetext{
${ }^{8}$ See http://www.ggdc.net/maddison/maddison-project/home.htm. In order to construct the emission per capita series at the regional level, we employ the population data from Maddison (2009) which is available up to 2009. For the 2010 values, we use the US Census Bureau database.
} 
Change (IPCC), we distinguish explicitly between Eastern Europe and Former USSR, divide the "old" OECD into Western Europe (old EU) and what we indicate as "Western Offshoots" (Australia, Canada, New Zealand, and the United States), while Japan together with the countries of the Middle East are grouped under the name "Other Asia". Finally, we split the IPCC region ALM into Africa and Latin America. In our empirical analysis we focus on two regions in particular: Western Offshoots (to be paired to Western Europe) and China (to be paired in the main text with Latin America).

In Table 1 some descriptive statistics for the nine regions are presented. For all variables it seems that there are no strong outliers. Considering only the mean, median, standard deviation, maximum and minimum values, all variables seem to be right tailed. We shall take logarithms of the per capita variables to correct for the skewness of the level variables.

Table 1: Descriptive statistics

\begin{tabular}{lcccccc}
\hline \hline & Units & Mean & Median & St. Dev. & Min. & Max. \\
\hline Emission & Tons (mln.) & 534.976 & 336.746 & 477.245 & 18.171 & 2259.856 \\
GDP & 1990 US\$ (bln) & 2496.036 & 1513.059 & 2573.609 & 183.017 & 11375.480 \\
Population & mln & 503.575 & 372.464 & 347.016 & 87.637 & 1620.231 \\
Emission pc. & $\mathrm{kg}$. & 1524.967 & 784.454 & 1532.208 & 39.255 & 5806.490 \\
GDP pc. & 1990 US\$ & 6118.600 & 4277.080 & 6369.410 & 448.022 & 30547.928 \\
Emission pc. $(\log )$ & & 6.705 & 6.665 & 1.236 & 3.670 & 8.667 \\
GDP pc. $(\log )$ & & 8.234 & 8.361 & 1.016 & 6.105 & 10.327 \\
\hline \hline
\end{tabular}

Note: Descriptive statistics are for the period 1950 - 2010. Total number of observation is 549.

In Figure 1 GDP per capita series of the regions are presented. Three groups can be distinguished. Western Offshoots and Western Europe have the highest income per capita. India and Africa are always in the lowest income group. Other Asia shows a gradual rise of income per capita and is part of the middle income group since the 1970s. GDP per capita for China started to grow later but faster and is part of the middle income group only recently. Eastern Europe, Former USSR, and Latin America stay in the middle income group throughout the period, although Former USSR experiences a decline following its collapse in 1990.

Figure 2 illustrates the corresponding $\mathrm{CO}_{2}$ emissions per capita. This figure shows some clear differences compared to Figure 1. First, the high emission group is limited to only one region, namely, Western Offshoot. Second, the middle emission group consists of former USSR, Eastern and Western Europe, and, recently, China. Third, emission growth per capita lags behind compared to GDP growth per capita for most regions. Finally, the highest emission regions seem to reflect a turning point at some point in time which is suggestive evidence for the EKC hypothesis. 
Figure 1: GDP Per Capita (thousand US $\$$ - 1990)

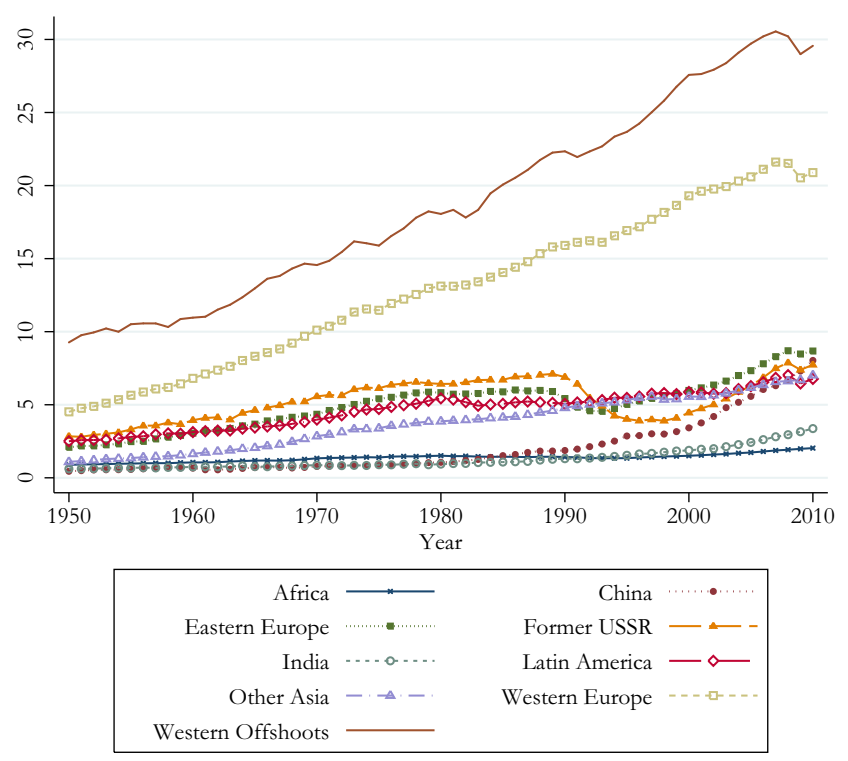

Figure 2: $\mathrm{CO}_{2}$ Emission Per Capita (ton)

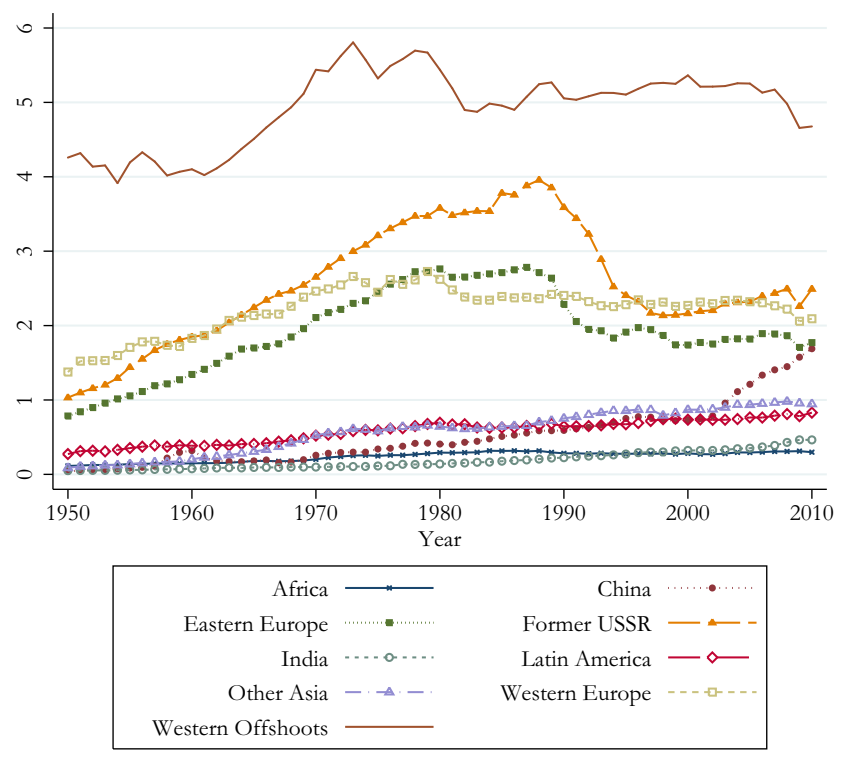


Next, we turn to the stationarity properties of our variables, considering our dataset as a panel including all nine regions. To test the stationarity of our variables in levels, we focus on the second generation panel data unit root tests, that take cross sectional correlation into account. Here, we focus on Bai and Ng (2004). Sen (2014) also reports the outcomes of other second generation unit root tests. ${ }^{9}$

Bai and Ng (2004) consider a multi-factor framework called "Panel Analysis of Nonstationarity in Idiosyncratic and Common Components" (PANIC) where the factors and idiosyncratic components are analyzed separately and hence allow for cross-unit cointegration. Furthermore, this method allows testing the number of factors with a unit root. Their model is as follows:

$$
\begin{aligned}
z_{i t} & =d_{i t}+\lambda_{i}^{\prime} F_{t}+E_{i t} \\
F_{t} & =F_{t-1}+\eta_{t} \\
E_{i t} & =\rho_{i} E_{i, t-1}+e_{i t}
\end{aligned}
$$

where $z_{i t}$ is the variable under consideration, with index $i$ (in our case) referring to region $i$ and index $t$ to year $t$, where $F_{t}$ is the vector of common factors, $E_{i t}$ is the idiosyncratic component, and $d_{i t}$ is the deterministic component of the data generating process which indicates whether the model includes a constant or a trend. The disturbances $\eta_{t}$ and $e_{i t}$ are assumed to be white noise processes. ${ }^{10}$

In this data generating process, one or more of the common factors might follow a random walk. Therefore, the standard factor analysis does not apply to identify the factor loadings. To deal with this issue, Bai and $\mathrm{Ng}$ (2004) suggest basing the principal component analysis on the first differences of the series. The standard PANIC analysis uses the selection criteria suggested by Bai and $\mathrm{Ng}$ (2002) to determine the number of common factors. However, this criterion performs poorly when the cross-sectional dimension is small, like in our case. So, in order to apply these tests, we assume the number of common factors to be at most three.

In Table 2 the results of the Bai and Ng test are presented. The first column indicates the given number of common factors which is assumed to be one, two, or three. In order to investigate the number of common factors with a unit root, the Bai and $\mathrm{Ng}$ (2004) method applies ADF unit root tests, labeled as "ADF" in Table 2. In case of more than one common factor, individual ADF tests may over-state the number of common stochastic trends (Bai and $\mathrm{Ng}, 2004$ ), since only the space spanned by the factors can be estimated. Therefore,

\footnotetext{
${ }^{9}$ Sen (2014) contains as one of the chapters a previous version of the current paper. This chapter in Sen (2014) includes an appendix, also presenting results of univariate unit root tests and first generation panel data unit root tests. When investigating cross sectional dependence, Sen (2014) clearly finds evidence for cross sectional dependence (both via common factors and via idiosyncratic components).

${ }^{10}$ The $r$-dimensional disturbance term $\eta_{t}$ is modeled as $\eta_{t}=C(L) u_{t}$, with $C(L)=\sum_{j=0}^{\infty} C_{j} L^{j}$ and $u_{t}$ i.i.d., where $\operatorname{rank}(C(1))=r_{1}$, with $0 \leq r_{1} \leq r$ the number of $\mathrm{I}(1)$ factors and $r-r_{1}$ the number of stationary factors.
} 
Bai and $\mathrm{Ng}(2004)$ suggest two tests $\left(M Q_{f}\right.$ and $\left.M Q_{c}\right)$, which are modified versions of the cointegration tests suggested by Stock and Watson (1988). The null hypothesis states the number of common stochastic trends against the alternative that it is less than the stated number in the null hypothesis. The test is applied successively by decreasing the number of stochastic trends in the null hypothesis as long as it is rejected.

For the idiosyncratic components, Bai and $\mathrm{Ng}$ (2004) provide two test statistics, one that is asymptotically normally distributed $\left(B N_{N}\right)$ and the other one that has an asymptotic chisquare distribution $\left(B N_{\xi^{2}}\right)$. Both tests depend on pooling the $p$-values from the ADF tests applied to individual idiosyncratic components.

The results in Table 2 indicate that there are likely multiple common factors with a unit root, while also the idiosyncratic components of both the GDP and the emission series seem to have a unit root. Given these outcomes, we shall proceed under the assumption that both the GDP and the emission series are nonstationary, in line with the findings of Wagner (2008) who also applied the PANIC analysis (and other tests) to carbon dioxide and GDP per capita, using data over 100 countries during the period 1950 to 2000.

In our analysis, we shall use pairwise differenced emissions as dependent variables. As follows from (4), pairwise differencing does not eliminate the effect of unit roots via the common factors, unless $\lambda_{i}$ of two different regions would be the same. However, Sen (2014) finds unit roots in the (investigated) pairwise differenced variables. Thus, we shall proceed under the assumption that not only GDP and the emission series are nonstationary, but also the (investigated) pairwise differences.

\section{Estimation Strategies}

In this section we discuss our estimation strategies for estimating (3), taking into account the nonstationarity properties found in the previous section. First, we rewrite (3) as

$$
y_{i k, t}=f_{c}\left(x_{i t}, i\right)-f_{c}\left(x_{k t}, k\right)+\varepsilon_{c, i k, t} .
$$

with $y_{i k, t}=y_{i t}-y_{k t}$ and $\varepsilon_{c, i k, t}=\varepsilon_{c, i t}-\varepsilon_{c, k t}$. Given a pair $c=\{i, k\}$, we consider as benchmark the "efficient nonstationary nonlinear least squares" (EN-NLS) estimator of Chang et al. (2001). We use the Fully Modified (FM)-OLS estimator of Wagner and Hong (2015) for comparison. To select a pair $c=\{i, k\}$ and to validate these two parametric approaches we apply the nonparametric approach by Schienle (2013).

The benchmark EN-NLS estimator of Chang et al. (2001) assumes that (5) can be written as

$$
y_{i k, t}=q_{c}\left(x_{t}, \beta\right)+\varepsilon_{c, i k, t},
$$


Table 2: Bai\&Ng (2004) Panel Unit Root Test

\begin{tabular}{|c|c|c|c|c|c|c|}
\hline & \multirow[t]{2}{*}{$\begin{array}{c}\text { Number of } \\
\text { Common Factors }\end{array}$} & \multicolumn{3}{|c|}{$\begin{array}{c}\text { Number of } \\
\text { Stochastic Trends }\end{array}$} & \multicolumn{2}{|c|}{$\begin{array}{l}\text { Idiosyncratic } \\
\text { Components }\end{array}$} \\
\hline & & $\mathrm{ADF}$ & $\mathrm{MQ}_{c}$ & $\mathrm{MQ}_{f}$ & $\mathrm{BN}_{N}$ & $\mathrm{BN}_{\chi^{2}}$ \\
\hline & \multicolumn{6}{|c|}{ Model with individual intercept } \\
\hline \multirow[t]{3}{*}{$\log ($ Emission pc. $)$} & 1 & 1 & & & 0.938 & 0.964 \\
\hline & 2 & & 2 & 2 & 0.903 & 0.926 \\
\hline & 3 & & 3 & 3 & 0.831 & 0.834 \\
\hline \multirow[t]{4}{*}{$\log ($ GDP pc. $)$} & 1 & 1 & & & 0.574 & 0.532 \\
\hline & 2 & & 2 & 2 & 0.460 & 0.412 \\
\hline & 3 & & 3 & 3 & 0.803 & 0.798 \\
\hline & \multicolumn{6}{|c|}{ Model with individual intercept and trend } \\
\hline \multirow[t]{3}{*}{$\log ($ Emission pc. $)$} & 1 & 1 & & & 0.957 & 0.983 \\
\hline & 2 & & 2 & 2 & 0.468 & 0.425 \\
\hline & 3 & & 3 & 3 & 0.851 & 0.860 \\
\hline \multirow[t]{3}{*}{$\log ($ GDP pc. $)$} & 1 & 1 & & & 0.954 & 0.980 \\
\hline & 2 & & 2 & 2 & 0.636 & 0.598 \\
\hline & 3 & & 3 & 3 & 0.641 & 0.605 \\
\hline
\end{tabular}

Unit root tests on the common factors are conducted at the $5 \%$ significance level. For the idiosyncratic components, $p$-values from the pooled unit root tests are presented, based on the Augmented Dickey-Fuller (ADF) tests on the individual series, and rejection indicates stationarity. The column "number of common factors" indicates the imposed number of common factors. Next, "the number of stochastic trends" indicates how many of these common factors are non-stationary. 
for some known function $q_{c}$ depending on $x_{t}=\left(x_{i t}, x_{k t}\right)^{\prime}$ and depending on an unknown, finitedimensional parameter vector $\beta$, that is to be estimated, and where $\varepsilon_{c, i k, t}$ is some stationary error process. The possible nonlinear transformation of the nonstationary regressors in (6) requires a different asymptotic theory than in case of nonlinear least squares with stationary regressors. ${ }^{11}$

In line with (5), we take $q_{c}$ to be separable in $x_{i t}$ and $x_{k t}$. Moreover, we shall assume that the separable parts are polynomials up to some order, where the order will be determined as part of the empirical analysis. ${ }^{12}$ These assumptions allow us to compare our benchmark with the Fully Modified (FM)-OLS considered by Wagner and Hong (2015). This latter estimation approach assumes polynomials in terms of $x_{i t}$ and $x_{k t}$ as regression function right from the start. $^{13}$

The parametric estimation of (6) with nonstationary regressors requires a cointegration relationship, i.e., the residuals in the regression equations should satisfy specific stationarity assumptions. Given the choice for a specification in terms of polynomials, we are dealing with Cointegrating Polynomial Regressions (CPRs), using the terminology of Wagner and Hong (2015). For such CPRs, Wagner and Hong (2015) and Wagner (2012) developed a series of residual based nonlinear cointegration tests, which we employ in order to verify the underlying cointegration assumption in our estimations.

Wagner and Hong (2015) propose a KPSS test on the residuals of the polynomial regression estimation. As in the linear case, the KPSS test is inclined to over-reject the null hypothesis of having a cointegrating relationship. In order to mitigate this problem, Wagner and Hong (2015) also propose a sub-sample KPSS test as in Choi and Saikkonen (2010). The null hypothesis in these KPSS type tests is cointegration. As alternative, they provide a variance ratio test under the null of no-cointegration by extending the Phillips and Ouliaris (1990) test for linear cointegration to polynomial cointegration. In our application we use all three tests.

To select the couples $c=\{i, k\}$ and to validate our parametric estimations, we use a nonparametric estimator avoiding a potential functional misspecification. Recently, Schienle (2013) shows how to generalize the nonparametric smooth backfitting estimation for additive models suggested by Mammen et al. (1999) to account for non-stationary regressions with many covariates. We focus on the special case where the two income components have the same type of nonstationarity (using the terminology of Schienle, 2013). For the paired GDP-s per capita this seems to be a reasonable approximation. ${ }^{14}$ If so, Schienle's general-

\footnotetext{
${ }^{11}$ For details we refer to Chang et al. (2001). EN-NLS estimation also allows to incorporate a linear trend and stationary regressors, in addition to multiple I(1) regressors. In our case, we do not have stationary variables, but only two nonstationary variables as regressors in (6).

${ }^{12} \mathrm{As}$ a consequence, the function $q_{c}$ is an asymptotically homogeneous function, using the terminology of Chang et al. (2001).

${ }^{13}$ The difference in assumptions between Chang et al. (2001) and Wagner and Hong (2015) is minor, given our choice to model $q_{c}$ in terms of polynomials: see page 5 of Wagner and Hong (2015).

${ }^{14}$ Cointegration tests for the GPD-s per capita in the paired regions, reported in Sen (2014), suggest that
} 
ized estimator is the smooth backfitting estimator, see Schienle (2013) for further details. ${ }^{15}$ An accessible description of the smooth backfitting estimator including its computation in a practical application can be found in Nielsen and Sperlich (2005).

In pairwise differencing estimations, it is possible to calibrate the time effects. From equation (3), we obtain the emissions depending on the GDP per capita of the region $i$ as $\widehat{f}_{c}\left(x_{i t}, i\right)$ and region $k$ as $\widehat{f}_{c}\left(x_{k t}, k\right)$, where $\widehat{f}_{c}$ is the estimated $f_{c}$ from the pairwise differencing estimations. The time effect of each region is constructed by subtracting the income effects from the observed emissions as $\hat{d}_{c}(i, t)=y_{i t}-\widehat{f}_{c}\left(x_{i t}, i\right)$ for region $i$, and $\hat{d}_{c}(k, t)=y_{k, t}-$ $\widehat{f}_{c}\left(x_{k t}, k\right)$ for region $k$. The time effects are homogeneous across paired regions. Therefore, in order to calibrate the time effects, we average these two time effects. ${ }^{16}$

One final issue is the choice to pair regions. Melenberg et al. (2011) propose to choose pairs on the basis of a so-called "Goodness-of-Fit ( $\mathrm{GoF}$ ) prior": among all candidate regions choose the pair region such that pairwise differencing estimation gives the lowest sum of squared errors. In this paper, we use the nonparametric non-stationary estimator suggested by Schienle (2013) to calculate the sum of squared errors. When applying this estimator we use Gaussian (product) kernels. We check for sensitivity to boundary correction methods, such as normalization, local linearization, and reflection. ${ }^{17}$ For nonstationary multivariate kernel regressions, the bandwidth selection is still an open question. As argued by Schienle (2013) it seems plausible to choose a larger bandwidth compared to the stationary case. For that reason we use, next to Silverman's rule of thumb, the normal scale rule, the direct plug-in rule, and also the oversmoothing rule. ${ }^{18}$ We check for sensitivity to these bandwidth choices by increasing the selected bandwidths up to a factor two.

\section{Estimation Results}

In this section we present the estimation results. Out of the nine regions we focus on China and Western Offshoots. The estimation results of the other regions are presented in the appendix. Using the selection procedure explained at the end of the previous section, we always couple Western Offshoots to Western Europe, but depending on the combination of boundary correction method and bandwidth choice, we couple China most often to Latin America, but sometimes to India or Former USSR. For these latter pairs (i.e., "China and Latin America", "China and India", and "China and Former USSR") the resulting parametric

\footnotetext{
there is a cointegrating relationship between the paired GDP-s per capita.

${ }^{15}$ The error terms in the Schienle (2013) approach also have to satisfy specific conditions. However, we are not aware of any formal way to test these conditions.

${ }^{16}$ In our companion paper, we model these calibrated time effects as a function of time to generate forecasts of future carbon dioxide emissions.

${ }^{17}$ See, for example, Karunamunia and Alberts (2005).

${ }^{18}$ The direct plug-in rule is a variant of the Sheather-Jones plug-in bandwidth estimation. See, for example, Wand and Jones (1995) for the details about these bandwidth selection procedures.
} 
outcomes for China (to be discussed next) turn out to be quite similar, thus robust to the bandwidth choice. In the sequel, we present the outcomes for China coupled to Latin America (as this region is chosen in the majority of cases considered). ${ }^{19}$ A sensitivity check by taking the two alternative best pairs is presented in the appendix.

Using our selected pairs, we apply EN-NLS as our benchmark approach. For $c=\{i, k\}$, we consider polynomials up to order five for both $f_{c}(\cdot, i)$ and $f_{c}(\cdot, k)$. We present the estimation results for the five polynomials (from order one to five) for China in Table 3 and for Western Offshoots in Table 4. For each polynomial we only include the corresponding "best" polynomial of the paired region. To select the "best" polynomials, we use the BIC criterion, including in the comparison only the models whose highest order polynomial term is significantly different from zero (at the $10 \%$ level). Thus, for China, we only make a comparison between the first, fourth, and fifth order polynomial, and for Western Offshoots we only compare the first, second, and fifth order polynomial. Using this selection criterion, we find that for both China and Western Offshoots the first order polynomial is the "best" fitting polynomial (with in both cases a third order polynomial as "best" fitting polynomial for the paired region, i.e., Latin America in case of China and Western Europe in case of Western Offshoots). The final column of both tables (with heading "FM-OLS") contains as comparison the FM-OLS estimates when using the same specification as the "best" EN-NLS estimates (i.e., in both cases a first order polynomial vs. a third order polynomial).

Figure 3 for $i=$ China and Figure 4 for $i=$ Western Offshoot illustrate $\widehat{f}_{c}\left(x_{i t}, i\right), \widehat{\lambda}_{c}(t)$, their sum, and $y_{i t}$ as a function of time $t$, with time $t$ running over the sample period. The pairwise differencing estimation does not identify the levels of these curves. Therefore, we normalize the curves such that the level of the sample average for each curve is equal to the average level of the observed emission in that region. For both China and Western Offshoot we find a clear upward trending income effect. In case of China the calibrated time effect is also upward sloping, whereas in case of Western Offshoots the calibrated time effect is downward sloping, at least in the second half of the sample period.

Next, in Figure 5 we show the shapes of the income effects, i.e., $\widehat{f}_{c}(\cdot, i)$ over the sample range of GDP per capita, for both China and Latin America (left panel), and for both Western Offshoots and Western Europe (right panel). These graphs show the resulting income effect using the "best" EN-NLS estimates (i.e., using the parameter estimates of columns (1) of Tables 3 and 4) and the resulting income effect using the corresponding FM-OLS estimates (i.e., using the parameter estimates of columns "FM-OLS" of Tables 3 and 4). Since the levels

\footnotetext{
${ }^{19}$ For China the generalization of our approach to consider the paired region to be time-dependent (i.e., $c=\left\{i,\left(k_{1}, \cdots, k_{T}\right)\right\}$ instead of $\left.c=\{i, k\}\right)$ might be relevant: if for each paired region the goodness-of-fit is considered to be poor, or if the pairing of the best fitting region does not turn out to be very robust, we might consider different pairing regions during different parts of the sample period to improve the goodness-of-fit. However, in this paper we do not consider this extension, also because the results for China itself seem to be robust (i.e., not very sensitive to the paired region).
} 
Table 3: Pairwise Differenced EN-NLS Estimations China

\begin{tabular}{|c|c|c|c|c|c|c|}
\hline & (1) & (2) & (3) & (4) & $(5)$ & FM-OLS \\
\hline \multirow[t]{2}{*}{$\log (\text { GDP pc. })^{1}$} & $0.581^{* * *}$ & $2.719^{*}$ & 10.294 & $-334.037^{*}$ & 0.000 & $0.690^{* * *}$ \\
\hline & $(0.096)$ & $(1.462)$ & (16.909) & $(180.411)$ & (.) & $(0.096)$ \\
\hline \multirow[t]{2}{*}{$\log (\text { GDP pc. })^{2}$} & & -0.145 & -1.147 & $67.630^{*}$ & $-21.730^{*}$ & \\
\hline & & $(0.098)$ & $(2.224)$ & $(36.002)$ & $(12.390)$ & \\
\hline \multirow[t]{2}{*}{$\log (\text { GDP pc. })^{3}$} & & & 0.044 & $-6.036^{*}$ & $5.871^{*}$ & \\
\hline & & & $(0.097)$ & $(3.183)$ & $(3.276)$ & \\
\hline \multirow[t]{2}{*}{$\log (\text { GDP pc. })^{4}$} & & & & $0.201^{*}$ & $-0.590^{*}$ & \\
\hline & & & & $(0.105)$ & $(0.324)$ & \\
\hline \multirow[t]{2}{*}{$\log (\text { GDP pc. })^{5}$} & & & & & $0.021^{*}$ & \\
\hline & & & & & $(0.011)$ & \\
\hline \multirow[t]{2}{*}{ P-log (GDP pc. $)^{1}$} & $-1035.780^{* * *}$ & $-1402.189^{* * *}$ & $-1339.121^{* * *}$ & 0.000 & $-1464.623^{* * *}$ & $-1219.0^{* * *}$ \\
\hline & $(242.873)$ & $(339.640)$ & $(365.089)$ & $()$. & $(359.336)$ & $(265.500)$ \\
\hline \multirow[t]{2}{*}{ P-log (GDP pc. $)^{2}$} & $122.359^{* * *}$ & $167.193^{* * *}$ & $159.556^{* * *}$ & $-89.042^{* * *}$ & $174.212^{* * *}$ & $143.8^{* * *}$ \\
\hline & $(29.147)$ & $(41.113)$ & $(44.144)$ & $(21.521)$ & $(43.407)$ & $(30.770)$ \\
\hline \multirow[t]{2}{*}{ P-log(GDP pc. $)^{3}$} & $-4.816^{* * *}$ & $-6.642^{* * *}$ & $-6.334^{* * *}$ & $14.109^{* * *}$ & $-6.904^{* * *}$ & $-5.651^{* * *}$ \\
\hline & $(1.166)$ & $(1.658)$ & $(1.779)$ & $(3.462)$ & $(1.747)$ & $(1.230)$ \\
\hline \multirow[t]{2}{*}{ P-log(GDP pc. $)^{4}$} & & & & $-0.628^{* * *}$ & & \\
\hline & & & & $(0.157)$ & & \\
\hline \multicolumn{7}{|l|}{ P-log (GDP pc. $)^{5}$} \\
\hline Adjusted $R^{2}$ & 0.908 & 0.909 & 0.907 & 0.911 & 0.912 & \\
\hline$A I C$ & -30.1 & -31.7 & -29.6 & -31.3 & -29.8 & \\
\hline$B I C$ & -19.7 & -21.3 & -17.2 & -16.8 & -13.2 & \\
\hline Observations & 59 & 59 & 59 & 59 & 59 & 59 \\
\hline
\end{tabular}

Notes: Paired region is Latin America. Polynomial terms of the pair region is indicated with "P-" at the lower part of the table. Standard errors are in parentheses.

Significance of the coefficients is labeled as ${ }^{*} p<0.10,{ }^{* *} p<0.05,{ }^{* * *} p<0.01$. 
Table 4: Pairwise Differenced EN-NLS Estimations Western Offshoots

\begin{tabular}{|c|c|c|c|c|c|c|}
\hline & $(1)$ & $(2)$ & $(3)$ & $(4)$ & $(5)$ & FM-OLS \\
\hline \multirow[t]{2}{*}{$\log (\text { GDP pc. })^{1}$} & $0.499^{* * *}$ & $7.914^{* * *}$ & 29.140 & 0.000 & 0.000 & $0.424^{* * *}$ \\
\hline & $(0.181)$ & $(2.079)$ & $(50.938)$ & (.) & $()$. & $(0.182)$ \\
\hline \multirow[t]{2}{*}{$\log (\text { GDP pc. })^{2}$} & & $-0.385^{* * *}$ & -2.519 & 1.945 & 0.000 & \\
\hline & & $(0.110)$ & $(5.116)$ & $(2.668)$ & $()$. & \\
\hline \multirow[t]{2}{*}{$\log (\text { GDP pc. })^{3}$} & & & 0.071 & -0.233 & $0.484^{*}$ & \\
\hline & & & $(0.171)$ & $(0.357)$ & $(0.264)$ & \\
\hline \multirow[t]{2}{*}{$\log (\text { GDP pc. })^{4}$} & & & & 0.008 & $-0.075^{*}$ & \\
\hline & & & & $(0.013)$ & $(0.041)$ & \\
\hline \multirow[t]{2}{*}{$\log (\text { GDP pc. })^{5}$} & & & & & $0.003^{*}$ & \\
\hline & & & & & $(0.002)$ & \\
\hline \multirow[t]{2}{*}{ P-log(GDP pc. $)^{1}$} & $50.799^{* * *}$ & $7.741^{* * *}$ & $8.312^{* * *}$ & $8.294^{* * *}$ & 0.000 & $54.380^{* * *}$ \\
\hline & $(13.809)$ & $(1.800)$ & $(2.310)$ & $(2.277)$ & (.) & $(13.820)$ \\
\hline \multirow[t]{2}{*}{ P-log(GDP pc. $)^{2}$} & $-5.302^{* * *}$ & $-0.396^{* * *}$ & $-0.428^{* * *}$ & $-0.427^{* * *}$ & 0.000 & $-5.679^{* * *}$ \\
\hline & $(1.480)$ & $(0.104)$ & $(0.131)$ & $(0.129)$ & $()$. & $(1.481)$ \\
\hline \multirow[t]{2}{*}{ P-log(GDP pc. $)^{3}$} & $0.186^{* * *}$ & & & & $0.503^{* *}$ & $0.199^{* * *}$ \\
\hline & $(0.053)$ & & & & $(0.219)$ & $(0.053)$ \\
\hline \multirow[t]{2}{*}{ P-log(GDP pc. $)^{4}$} & & & & & $-0.081^{* *}$ & \\
\hline & & & & & $(0.037)$ & \\
\hline \multirow[t]{2}{*}{ P-log(GDP pc. $)^{5}$} & & & & & $0.003^{* *}$ & \\
\hline & & & & & $(0.002)$ & \\
\hline Adjusted $R^{2}$ & 0.832 & 0.831 & 0.829 & 0.829 & 0.833 & \\
\hline$A I C$ & -253.8 & -253.0 & -253.2 & -253.2 & -254.6 & \\
\hline$B I C$ & -243.4 & -242.6 & -242.9 & -242.9 & -242.1 & \\
\hline Observations & 59 & 59 & 59 & 59 & 59 & 59 \\
\hline
\end{tabular}

Notes: Paired region is Western Europe. Polynomial terms of the pair region is indicated with "P-" at the lower part of the table. Standard errors are in parentheses.

Significance of the coefficients is labeled as ${ }^{*} p<0.10,{ }^{* *} p<0.05,{ }^{* * *} p<0.01$. 
Figure 3: Pairwise Differencing Estimations for China

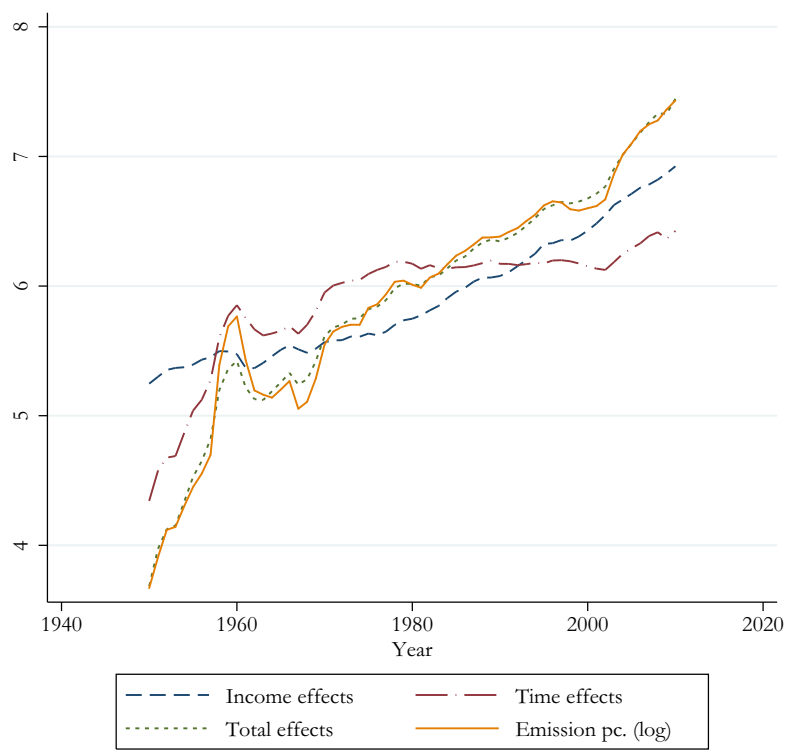

Explanation: This figure shows the estimated effects of the EN-NLS estimation for China when coupled with Latin America. All series are in logarithms. Levels of the estimated effects are normalized such that the means are equal to the mean of the observed emission series (in logs).

Figure 4: Pairwise Differencing Estimations for WO

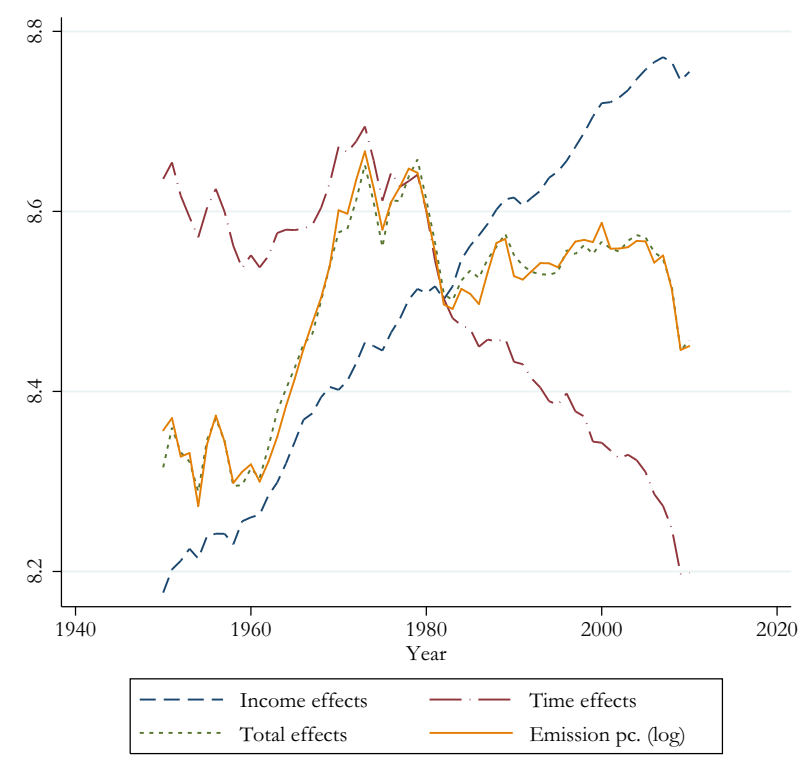

Explanation: This figure shows the estimated effects of the EN-NLS estimation for Western Offshoots when coupled with Western Europe. All series are in logarithms. Levels of the estimated effects are normalized such that the means are equal to the mean of the observed emission series (in logs). 
Figure 5: Comparison of income effects of the EN-NLS and FM-OLS estimations
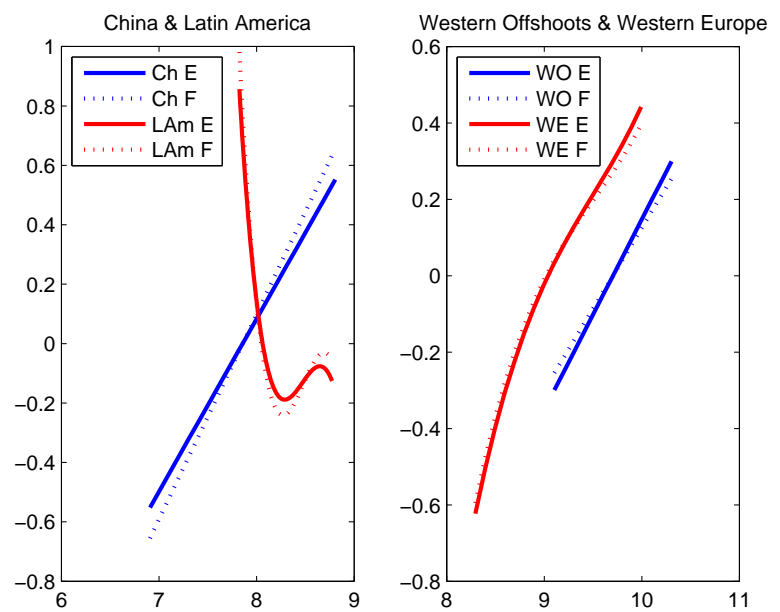

Explanation: This figure shows a comparison of the EN-NLS (E) estimates and the corresponding FM-OLS (F) estimates. The left panel compares the estimates for China (Ch) and Latin America (LAm). The right panel compares the estimates for Western Offshoots (WO) and Western Europe (WE).

are not identified, we set the level in these graphs such that in the middle of the region-specific sample range of GDP per capita the level is equal to zero.

As the figure shows, the EN-NLS and FM-OLS estimates yield rather similar outcomes. The common time effect of China and Latin America shown in Figure 3, is rather steep, leaving enough space for an increasing income effect for China, but too steep for an increasing income effect for Latin America. The reason is the rather spectacular growth, both in income and carbon dioxide emissions in China, while the corresponding growth in income and carbon dioxide emissions in Latin America was quite moderate, compared to China. Thus, relative to China, Latin America is showing a negative income effect over a large part of the sample range. However, relative to its own best fitting paired region (India), Latin America shows an almost flat (calibrated) time effect, and a clearly increasing income effect (see below). ${ }^{20}$

In Table 5 we present the results of various cointegrating tests for China and Western Offshoots. The results for the other regions are presented in the appendix. For each of the test statistics we present two versions. The first one (reported under the heading "1 stage" in Table 5) is the version where the long-run covariance matrix is computed from the residuals of OLS regression prior to calculating the Polynomial Cointegration Estimator, as suggested in Wagner and Hong (2015). For the second version (presented in the column labeled as "2 Stage") we recompute the long-run covariance matrix from the residuals of the Polynomial Cointegration Estimator prior to calculating the test statistics, cf. Wang and Wu (2012). Both approaches are asymptotically equivalent. The critical values for the sub-sample test

\footnotetext{
${ }^{20}$ See Section 2 for a detailed explanation of interpreting the results relative to another region.
} 
Table 5: Cointegration Tests

\begin{tabular}{|c|c|c|c|c|c|}
\hline & \multicolumn{2}{|c|}{ Test Statistics } & \multicolumn{3}{|c|}{ Critical Values } \\
\hline & 1 Stage & 2 Stage & $90 \%$ & $95 \%$ & $99 \%$ \\
\hline & \multicolumn{5}{|c|}{ China } \\
\hline \multicolumn{6}{|l|}{ H0: Cointegration } \\
\hline KPSS & 0.067 & 0.065 & 0.140 & 0.191 & 0.348 \\
\hline Sub-sample KPSS & 0.517 & 0.725 & 3.484 & 3.983 & \\
\hline \multicolumn{6}{|l|}{ H0: No cointegration } \\
\hline \multirow[t]{2}{*}{ Variance ratio test } & 37.993 & 42.293 & 39.676 & 47.702 & 63.828 \\
\hline & \multicolumn{5}{|c|}{ Western Offshoots } \\
\hline \multicolumn{6}{|l|}{ H0: Cointegration } \\
\hline KPSS & 0.074 & 0.090 & 0.137 & 0.193 & 0.342 \\
\hline Sub-sample KPSS & 0.964 & 1.076 & 3.741 & 4.220 & \\
\hline \multicolumn{6}{|l|}{ H0: No cointegration } \\
\hline Variance ratio test & 31.006 & 31.888 & 45.521 & 54.064 & 73.813 \\
\hline
\end{tabular}

can be found in Wagner and Hong (2015). The critical values for the KPSS test and the Variance Ratio test in case there is more than one covariate with higher order polynomials are not tabulated yet. For these cases, we present the critical values from our own Monte-Carlo simulations with 800 observations and 1600 replications.

In Table 5, the results from the KPSS tests and the sub-sample KPSS tests do not reject the null hypothesis of a cointegrating relationship for both China and Western Offshoots. The results from the variance ratio tests support this finding for China, but not for Western Offshoots. When the two-step procedure is applied, the null hypothesis of "no cointegration" is rejected for China at the $10 \%$ significance level. In case of the one-step procedure, the test statistic is insignificant at the margin. Overall, there is a strong evidence for a cointegrating relationship for China. However, for Western Offshoots, the variance ratio tests do not indicate a cointegrating relationship in contrast the KPSS tests. We find similar outcomes in case of the other regions (see appendix).

Finally, we confront the empirically-selected benchmark EN-NLS estimates with the 95\%confidence intervals based on the nonparametric non-stationary estimator (generalized smooth backfitting) suggested by Schienle (2013). ${ }^{21}$ The presented nonparametric estimates for China and Western Offshoots are based on employing univariate Gaussian kernel and their products for the multivariate density estimations in combination with using the direct plug-in bandwidth estimation method for each covariate. ${ }^{22}$ The confidence intervals are constructed as described

\footnotetext{
${ }^{21}$ See footnote 14 for some additional information.

${ }^{22}$ We apply the direct plug-in bandwidth estimation with five iterations. The estimated patterns are robust
} 
Figure 6: Comparison of parametric and non-parametric estimations
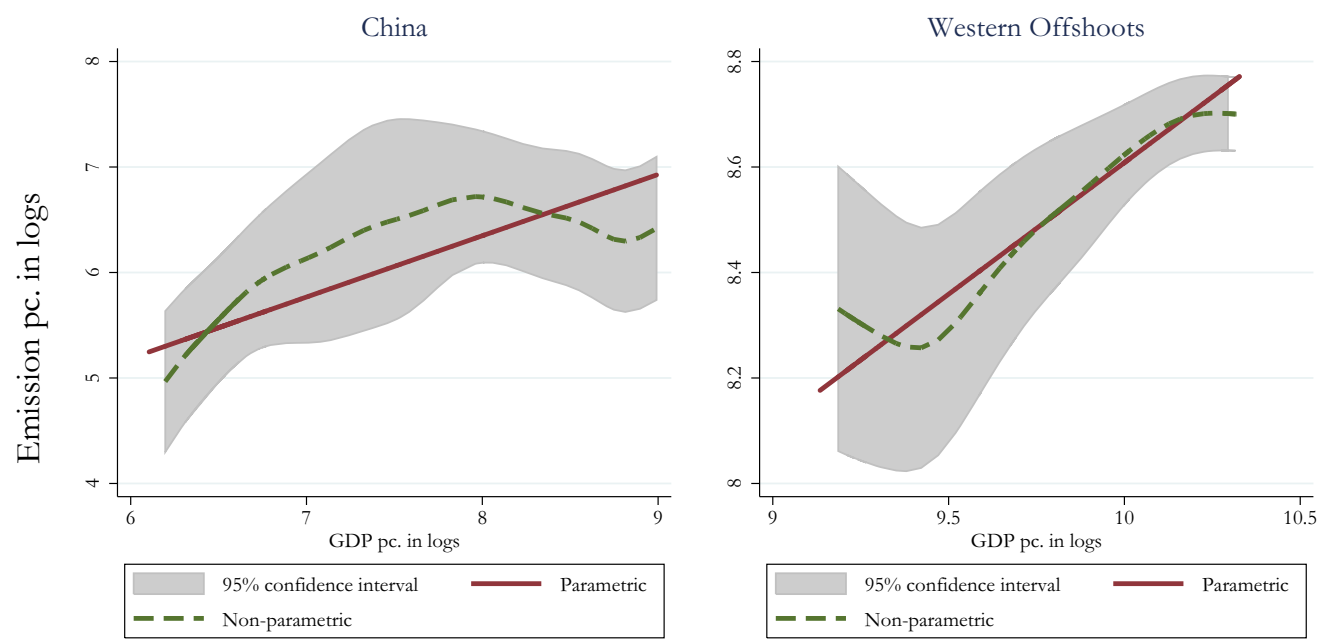

Explanation: This figure shows a comparison of the EN-NLS estimates and the non-parametric estimates. The left panel compares the estimates for China. The right panel compares the estimates for Western Offshoots. The $95 \%$ non-parametric confidence intervals from the non-parametric estimations are indicated by the shaded area. 
Figure 7: ENNLS Estimation for all regions
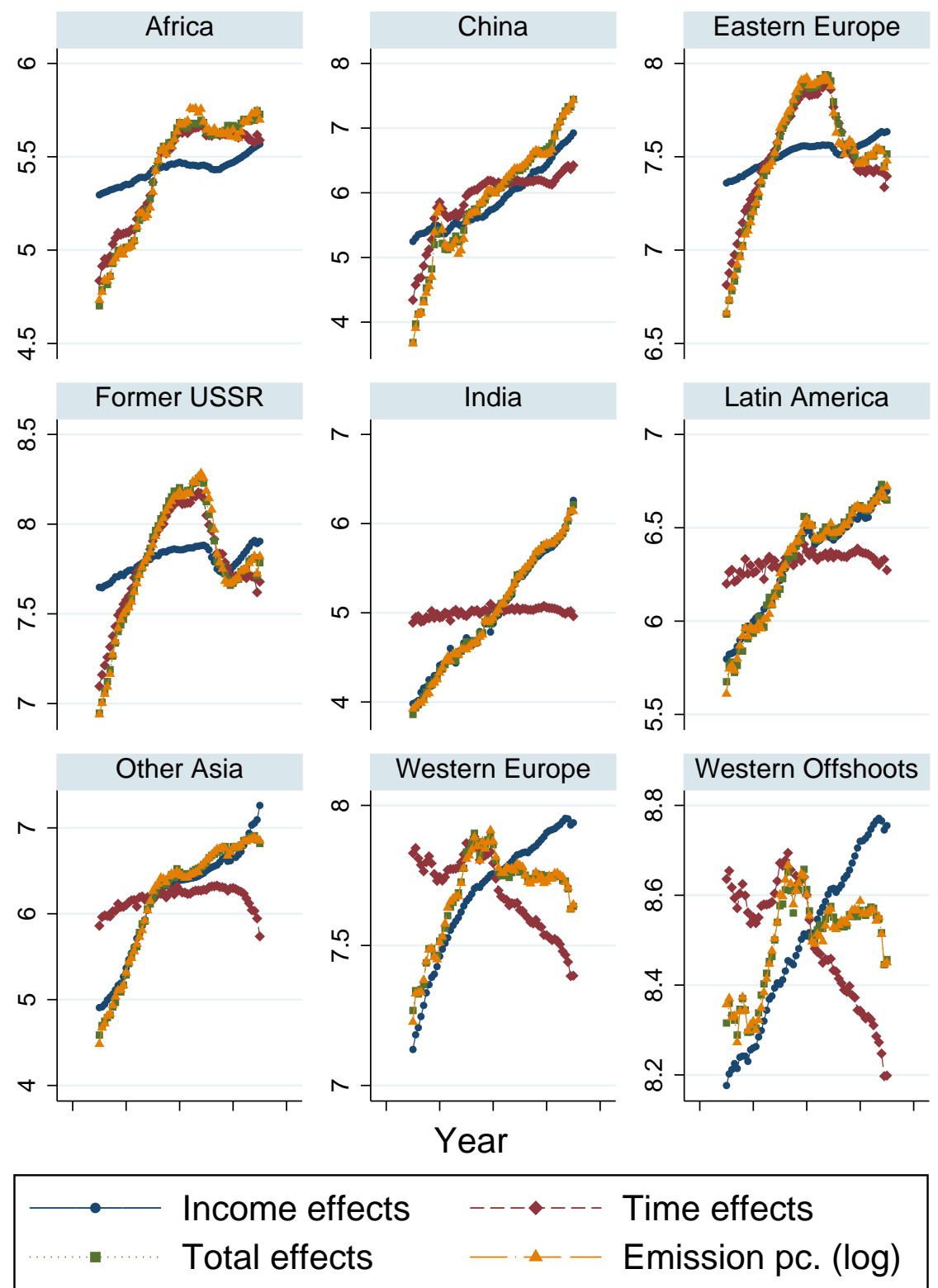

Explanation: This figure shows the estimated effects of the EN-NLS estimation for all regions. See the estimation tables for the pair regions. All series are in logarithms. Levels of the estimated effects are normalized such that the means are equal to the mean of observed emission series (in logs). 
in Nielsen and Sperlich (2005), see also Sen (2014). Figure 6 shows the results. In case of China the nonparametric and "best" parametric estimation results are very close. For Western Offshoots the nonparametric estimate shows somewhat more curvature than the "best" parametric one, but the latter clearly lies inside the confidence band.

Estimation results for all regions are presented in Figure 7. Related estimation tables and cointegration tests are provided in the appendix. The figure also includes the results for China and Western Offshoots in order to ease comparison of the estimated series across regions. The striking result is that the income effect is increasing for all regions. That is, holding the time effects constant, scaling up economic activity leads to higher emissions. The estimated patterns for the income effects indicate smoothly increasing patterns. Indeed, the degree of the chosen polynomial for five out of nine regions is one. On the other hand, the estimated time effects follow heterogeneous patterns across regions. It is clearly decreasing for Western Offshoots and Western Europe which are the advanced economies in our sample. That is, time effects play a mitigating role in high income regions, but this is not the case for other regions. This result is in line with the theoretical arguments in the EKC literature that technological effects and compositional effects can reduce emissions at high income levels. Interestingly, our results also indicate that these factors are not sufficient to create a down-turn in emissions and hence do not support an inverted U-shaped relationship between pollution and income.

\section{Conclusion}

In this paper we deal with two econometric issues related to the traditional quantification and estimation of the Environmental Kuznets Curves (EKCs), namely the lack of robustness which is likely to be related to fundamental identification problem of the income effect, and the need to use nonlinear estimation techniques that can handle non-stationary data. Using the PANIC-approach proposed by Bai and Ng (2004) we find, in line with the earlier literature, strong evidence that carbon dioxide emissions and GDP per capita are non-stationary. Estimation procedures suitable for nonstationarity is therefore essential. Furthermore, we use the estimation approach suggested by Vollebergh et al. (2009) to identify the income effect of regions in the reduced form EKC literature.

Our pairwise differencing estimations do not yield income effects that support the EKC hypothesis. For both China and Western Offshoots (the regions we focus on) we find clearly

to using a wide range of kernels including those employing boundary correction methods such as normalization, local linearization, and reflection, and robust to using alternative bandwidth selection methods, namely Silverman, normal scale rule, and oversmoothing rule. As argued in Schienle (2013), the mentioned bandwidth selection methods, which are not designed for the non-stationary case, seem to yield too narrow bandwidths. Increasing the selected bandwidth, up to a factor two, leads to results that are more in line with the parametric estimations. The combination of the chosen methods affects the slope and the curvature of the estimated curves, but not the estimated patterns. In some cases, the income effects of Western Offshoots stay out of the confidence band for a few periods at the boundary values. 
increasing income effects. Moreover, the downward sloping time effects of Western Offshoots are not likely to compensate for the increasing income effects. This finding also applies to the other regions. A comparison of the parametric and nonparmetric estimation results reveals similar patterns, supporting our empirical findings.

A final observation is that our pairwise differencing approach yields consistent estimations of the identified income effect of a region relative to another region. Moreover, our finding of a positive income effect is consistent with the main findings in the theoretical literature, i.e. a scale effect would drive emissions systematically upward along any economic growth path (e.g. Brock and Taylor, 2005). In this literature declining emissions would be due to either sectoral shifts or technological change. Those effects are typically reflected by unmeasured temporal variablity correlated with emissions and picked up by our time effect. However, the time effects are only calibrated. A natural next step is to construct and estimate a model for the time effects using these calibrated time effects. This is a topic that we leave for future research.

\section{References}

Bai, J., Ng, S., 2002. Determining the number of factors in approximate factor models. Econometrica 70 (1), 191-221.

Bai, J., Ng, S., 2004. A PANIC attack on unit roots and cointegration. Econometrica 72 (4), $1127-1177$.

Boden, T., Marland, G., R., A., 2013. Global, regional, and national fossil-fuel $\mathrm{CO}_{2}$ emissions. Tech. rep., Carbon Dioxide Information Analysis Center, Oak Ridge National Laboratory, U.S. Department of Energy, Oak Ridge, Tenn., U.S.A.

Brock, W. A., Taylor, M. S., 2005. Economic growth and the environment: a review of theory and empirics. Handbook of economic growth 1, 1749-1821.

Chang, Y., Park, J., Phillips, P., 2001. Nonlinear econometric models with cointegrated and deterministically trending regressors. Econometrics Journal 4, 1-36.

Chertow, M., 2000. The IPAT Equation and Its Variants. Journal of Industrial Technology 4, $13-29$.

Choi, I., Saikkonen, P., 2010. Tests for nonlinear cointegration. Econometric Theory 26 (3), 682.

De Bruyn, S., van den Bergh, J., Opschoor, J., 1998. Economic growth and emissions: reconsidering the empirical basis of Environmental Kuznets Curves. Ecological Economics 25 (2), $161-175$. 
Dijkgraaf, E., Vollebergh, H., 2005. A test for parameter homogeneity in $\mathrm{CO}_{2}$ panel EKC estimations. Environmental \&3 Resource Economics 32 (2), 229-239.

Galeotti, M., Manera, M., Lanza, A., 2009. On the robustness of robustness checks of the Environmental Kuznets Curve hypothesis. Environmental and Resource Economics 42 (4), $551-574$.

Grossman, G., Krueger, A., 1991. Environmental impacts of a North American free trade agreement. Tech. rep., National Bureau of Economic Research.

Harbaugh, W. T., Levinson, A., Wilson, D. M., 2002. Reexamining the empirical evidence for an environmental kuznets curve. Review of Economics and Statistics 84 (3), 541-551.

Karlsen, H., Myklebust, T., Tjøstheim, D., 2007. Nonparametric estimation in a nonlinear cointegration type model. Annals of Statistics 35 (1), 252-299.

Karunamunia, R., Alberts, T., 2005. On boundary correction in kernel density estimation. Statistical Methodology 2, 191-212.

Maddison, A., 2009. Statistics on world population, GDP and per capita GDP, 1-2006 AD, 2008.

Mammen, E., Linton, O., Nielsen, J., 1999. The existence and asymptotic properties of a backfitting projection algorithm under weak conditions. The Annals of Statistics 27 (5), $1443-1490$.

Melenberg, B., Vollebergh, H., Dijkgraaf, E., 2011. Grazing the commons: Global carbon emissions forever? CentER Discussion Paper.

Millimet, D., List, J., Stengos, T., 2003. The environmental Kuznets curve: Real progress or misspecified models? Review of Economics and Statistics 85 (4), 1038-1047.

Muller-Furstenberger, G., Wagner, M., 2007. Exploring the environmental Kuznets hypothesis: Theoretical and econometric problems. Ecological Economics 62 (3), 648-660.

Nielsen, J., Sperlich, S., 2005. Smooth backfitting in practice. Journal of the Royal Statistical Society: Series B (Statistical Methodology) 67 (1), 43-61.

Perman, R., Stern, D., 2003. Evidence from panel unit root and cointegration tests that the environmental Kuznets curve does not exist. Australian Journal of Agricultural and Resource Economics 47 (3), 325-347.

Phillips, P. C., Ouliaris, S., 1990. Asymptotic properties of residual based tests for cointegration. Econometrica 58, 165-193. 
Schienle, M., 2013. Nonparametric nonstationary regression with many covariates. Tech. rep., School of Economics and Management, Leibniz University Hannover.

Sen, S., 2014. Essays in environmental and political economics. Vol. 397. CentER Dissertation Series.

Stern, D., 2004. The rise and fall of the environmental Kuznets curve. World development $32(8), 1419-1439$.

Stock, J. H., Watson, M. W., 1988. Testing for common trends. Journal of the American Statistical Association 83 (404), 1097-1107.

Vollebergh, H., Melenberg, B., Dijkgraaf, E., 2009. Identifying reduced-form relations with panel data: The case of pollution and income. Journal of Environmental Economics and Management 58 (1), 27-42.

Wagner, M., 2008. The carbon Kuznets curve: A cloudy picture emitted by bad econometrics? Resource and Energy Economics 30 (3), 388-408.

Wagner, M., 2012. The Phillips unit root tests for polynomials of integrated processes. Economics Letters 114 (3), 299-303.

Wagner, M., Hong, S. H., 2015. Cointegrating polynomial regressions: Fully modified OLS estimation and inference. Econometric Theory, forthcoming Doi:10.1017/S0266466615000213.

Wand, M., Jones, M., 1995. Kernel Smoothing. Chapman \& Hall/CRC.

Wang, Q., Phillips, P., 2009. Asymptotic theory for local time density estimation and nonparametric cointegrating regression. Econometric Theory 25 (3), 710.

Wang, Q., Wu, N., 2012. Long-run covariance and its applications in cointegration regression. Stata Journal 12 (3), 525-542. 


\section{Appendix: Estimation Results Other Regions}

Table 6: Pairwise Differenced ENNLS Estimations Africa

\begin{tabular}{|c|c|c|c|c|c|}
\hline & $(1)$ & $(2)$ & (3) & (4) & $(5)$ \\
\hline \multirow[t]{2}{*}{$\log (\text { GDP pc. })^{1}$} & $0.329^{*}$ & -18.580 & 576.846 & 0.000 & 0.000 \\
\hline & $(0.183)$ & $(11.811)$ & $(374.089)$ & (.) & $()$. \\
\hline \multirow[t]{2}{*}{$\log (\text { GDP pc. })^{2}$} & & 1.294 & -80.561 & 39.091 & 0.000 \\
\hline & & $(0.808)$ & $(51.409)$ & $(26.036)$ & (.) \\
\hline \multirow[t]{2}{*}{$\log (\text { GDP pc. })^{3}$} & & & 3.750 & -7.276 & 3.527 \\
\hline & & & $(2.355)$ & $(4.766)$ & $(2.424)$ \\
\hline \multirow[t]{2}{*}{$\log (\text { GDP pc. })^{4}$} & & & & 0.381 & -0.738 \\
\hline & & & & $(0.245)$ & $(0.499)$ \\
\hline \multirow[t]{2}{*}{$\log (\text { GDP pc. })^{5}$} & & & & & 0.041 \\
\hline & & & & & $(0.027)$ \\
\hline \multirow[t]{2}{*}{ P-log (GDP pc. $)^{1}$} & $260.658^{* * *}$ & $249.341^{* *}$ & $535.033^{* *}$ & $527.581^{* * *}$ & $519.987^{* * *}$ \\
\hline & $(96.564)$ & $(95.432)$ & $(201.852)$ & $(196.518)$ & $(191.630)$ \\
\hline \multirow[t]{2}{*}{ P-log (GDP pc. $)^{2}$} & $-31.783^{* * *}$ & $-31.174^{* * *}$ & $-64.865^{* * *}$ & $-63.973^{* * *}$ & $-63.065^{* * *}$ \\
\hline & $(11.559)$ & $(11.403)$ & $(23.871)$ & $(23.237)$ & $(22.655)$ \\
\hline \multirow[t]{2}{*}{ P-log(GDP pc. $)^{3}$} & $1.291^{* * *}$ & $1.296^{* * *}$ & $2.620^{* * *}$ & $2.584^{* * *}$ & $2.548^{* * *}$ \\
\hline & $(0.461)$ & $(0.455)$ & $(0.941)$ & $(0.916)$ & $(0.893)$ \\
\hline \multicolumn{6}{|l|}{ P-log $(\text { GDP pc. })^{4}$} \\
\hline \multicolumn{6}{|l|}{ P-log (GDP pc. $)^{5}$} \\
\hline Adjusted $R^{2}$ & 0.328 & 0.346 & 0.365 & 0.366 & 0.366 \\
\hline$A I C$ & -155.5 & -156.2 & -157.0 & -157.1 & -157.1 \\
\hline$B I C$ & -147.2 & -145.9 & -144.6 & -144.6 & -144.6 \\
\hline Observations & 59 & 59 & 59 & 59 & 59 \\
\hline
\end{tabular}

Notes: Paired region is Latin America. Polynomial terms of the pair region is indicated with "P-" at the lower part of the table. Standard errors are in parentheses. Significance of the coefficients is labeled as ${ }^{*} p<0.10,{ }^{* *} p<0.05,{ }^{* * *} p<0.01$. 
Table 7: Pairwise Differenced ENNLS Eastern Europe

\begin{tabular}{|c|c|c|c|c|c|}
\hline & (1) & (2) & (3) & (4) & $(5)$ \\
\hline \multirow[t]{2}{*}{$\log (\text { GDP pc. })^{1}$} & $0.193^{* * *}$ & -0.103 & -23.622 & 0.000 & -101.314 \\
\hline & $(0.037)$ & $(0.910)$ & $(29.692)$ & (.) & $(257.954)$ \\
\hline \multirow[t]{2}{*}{$\log (\text { GDP pc. })^{2}$} & & 0.018 & 2.823 & -1.393 & 0.000 \\
\hline & & $(0.054)$ & $(3.541)$ & $(1.784)$ & $()$. \\
\hline \multirow[t]{2}{*}{$\log (\text { GDP pc. })^{3}$} & & & -0.111 & 0.223 & 2.784 \\
\hline & & & $(0.141)$ & $(0.283)$ & $(7.367)$ \\
\hline \multirow[t]{2}{*}{$\log (\text { GDP pc. })^{4}$} & & & & -0.010 & -0.326 \\
\hline & & & & $(0.013)$ & $(0.879)$ \\
\hline \multirow[t]{2}{*}{$\log (\text { GDP pc. })^{5}$} & & & & & 0.011 \\
\hline & & & & & $(0.031)$ \\
\hline \multirow[t]{2}{*}{ P-log(GDP pc. $)^{1}$} & $0.256^{* * *}$ & $0.253^{* * *}$ & $0.246^{* * *}$ & $0.246^{* * *}$ & $0.248^{* * *}$ \\
\hline & $(0.049)$ & $(0.050)$ & $(0.050)$ & $(0.051)$ & $(0.051)$ \\
\hline \multicolumn{6}{|l|}{ P-log (GDP pc. $)^{2}$} \\
\hline \multicolumn{6}{|l|}{ P-log (GDP pc. $)^{3}$} \\
\hline \multicolumn{6}{|l|}{ P-log(GDP pc. $)^{4}$} \\
\hline \multicolumn{6}{|l|}{ P-log (GDP pc. $)^{5}$} \\
\hline Adjusted $R^{2}$ & 0.322 & 0.311 & 0.303 & 0.303 & 0.293 \\
\hline$A I C$ & -169.3 & -167.4 & -166.0 & -166.0 & -166.1 \\
\hline$B I C$ & -163.1 & -159.1 & -155.7 & -155.6 & -155.8 \\
\hline Observations & 59 & 59 & 59 & 59 & 59 \\
\hline
\end{tabular}

Notes: Paired region is Former USSR. Polynomial terms of the pair region is indicated with "P-" at the lower part of the table. Standard errors are in parentheses. Significance of the coefficients is labeled as ${ }^{*} p<0.10,{ }^{* *} p<0.05,{ }^{* * *} p<0.01$. 
Table 8: Pairwise Differenced ENNLS Estimations Former USSR

\begin{tabular}{|c|c|c|c|c|c|}
\hline & $(1)$ & $(2)$ & $(3)$ & $(4)$ & $(5)$ \\
\hline \multirow[t]{2}{*}{$\log (\text { GDP pc. })^{1}$} & $0.256^{* * *}$ & 0.924 & 106.317 & 0.000 & 0.000 \\
\hline & $(0.049)$ & $(1.855)$ & $(83.290)$ & (.) & (.) \\
\hline \multirow[t]{2}{*}{$\log (\text { GDP pc. })^{2}$} & & -0.039 & -12.513 & 6.379 & 0.000 \\
\hline & & $(0.109)$ & $(9.852)$ & $(4.937)$ & (.) \\
\hline \multirow[t]{2}{*}{$\log (\text { GDP pc. })^{3}$} & & & 0.492 & -0.999 & 0.514 \\
\hline & & & $(0.388)$ & $(0.778)$ & $(0.390)$ \\
\hline \multirow[t]{2}{*}{$\log (\text { GDP pc. })^{4}$} & & & & 0.044 & -0.090 \\
\hline & & & & $(0.034)$ & $(0.069)$ \\
\hline \multirow[t]{2}{*}{$\log (\text { GDP pc. })^{5}$} & & & & & 0.004 \\
\hline & & & & & $(0.003)$ \\
\hline \multirow[t]{2}{*}{ P-log $(\text { GDP pc. })^{1}$} & $0.193^{* * *}$ & $0.196^{* * *}$ & $0.213^{* * *}$ & $0.214^{* * *}$ & $0.214^{* * *}$ \\
\hline & $(0.037)$ & $(0.039)$ & $(0.040)$ & $(0.040)$ & $(0.040)$ \\
\hline \multicolumn{6}{|l|}{ P-log $(\text { GDP pc. })^{2}$} \\
\hline \multicolumn{6}{|l|}{ P-log (GDP pc. $)^{3}$} \\
\hline \multicolumn{6}{|l|}{ P-log (GDP pc. $)^{4}$} \\
\hline \multicolumn{6}{|l|}{ P-log (GDP pc. $)^{5}$} \\
\hline Adjusted $R^{2}$ & 0.322 & 0.311 & 0.327 & 0.327 & 0.328 \\
\hline$A I C$ & -169.3 & -167.5 & -169.0 & -167.0 & -167.0 \\
\hline$B I C$ & -163.1 & -159.1 & -160.7 & -156.6 & -156.6 \\
\hline Observations & 59 & 59 & 59 & 59 & 59 \\
\hline
\end{tabular}

Notes: Paired region is Eastern Europe. Polynomial terms of the pair region is indicated with "P-" at the lower part of the table. Standard errors are in parentheses. Significance of the coefficients is labeled as ${ }^{*} p<0.10,{ }^{* *} p<0.05,{ }^{* * *} p<0.01$. 
Table 9: Pairwise Differenced ENNLS Estimations India

\begin{tabular}{|c|c|c|c|c|c|}
\hline & (1) & $(2)$ & (3) & $(4)$ & $(5)$ \\
\hline \multirow[t]{2}{*}{$\log (\text { GDP pc. })^{1}$} & $1.350^{* * *}$ & $10.433^{* * *}$ & $72.286^{* * *}$ & $-1139.631^{* * *}$ & 0.000 \\
\hline & $(0.080)$ & $(0.992)$ & $(21.299)$ & $(323.337)$ & (.) \\
\hline \multirow[t]{2}{*}{$\log (\text { GDP pc. })^{2}$} & & $-0.642^{* * *}$ & $-9.097^{* * *}$ & $243.307^{* * *}$ & $-74.074^{* * *}$ \\
\hline & & $(0.067)$ & $(2.911)$ & $(67.340)$ & $(22.835)$ \\
\hline \multirow[t]{2}{*}{$\log (\text { GDP pc. })^{3}$} & & & $0.385^{* * *}$ & $-22.938^{* * *}$ & $21.183^{* * *}$ \\
\hline & & & $(0.133)$ & $(6.225)$ & $(6.323)$ \\
\hline \multirow[t]{2}{*}{$\log (\text { GDP pc. })^{4}$} & & & & $0.807^{* * *}$ & $-2.255^{* * *}$ \\
\hline & & & & $(0.215)$ & $(0.656)$ \\
\hline \multirow[t]{2}{*}{$\log (\text { GDP pc. })^{5}$} & & & & & $0.085^{* * *}$ \\
\hline & & & & & $(0.024)$ \\
\hline \multirow[t]{2}{*}{ P-log(GDP pc. $)^{1}$} & $457.881^{* * *}$ & $0.738^{* * *}$ & $0.966^{* * *}$ & $0.905^{* * *}$ & $0.897^{* * *}$ \\
\hline & $(115.141)$ & $(0.086)$ & $(0.111)$ & $(0.101)$ & $(0.101)$ \\
\hline \multirow[t]{2}{*}{ P-log $(\text { GDP pc. })^{2}$} & $-56.407^{* * *}$ & & & & \\
\hline & $(13.862)$ & & & & \\
\hline \multirow[t]{2}{*}{ P-log $(\text { GDP pc. })^{3}$} & $2.317^{* * *}$ & & & & \\
\hline & $(0.556)$ & & & & \\
\hline \multicolumn{6}{|l|}{ P-log (GDP pc. $)^{4}$} \\
\hline \multicolumn{6}{|l|}{ P-log (GDP pc. $)^{5}$} \\
\hline Adjusted $R^{2}$ & 0.955 & 0.970 & 0.974 & 0.979 & 0.979 \\
\hline$A I C$ & -129.5 & -152.5 & -159.0 & -172.3 & -172.2 \\
\hline$B I C$ & -121.2 & -144.1 & -148.6 & -161.9 & -161.8 \\
\hline Observations & 59 & 59 & 59 & 59 & 59 \\
\hline
\end{tabular}

Notes: Paired region is Latin America. Polynomial terms of the pair region is indicated with "P-" at the lower part of the table. Standard errors are in parentheses. Significance of the coefficients is labeled as ${ }^{*} p<0.10,{ }^{* *} p<0.05,{ }^{* * *} p<0.01$. 
Table 10: Pairwise Differenced ENNLS Estimations Latin America

\begin{tabular}{|c|c|c|c|c|c|}
\hline & (1) & (2) & (3) & (4) & $(5)$ \\
\hline \multirow[t]{2}{*}{$\log (\text { GDP pc. })^{1}$} & $0.905^{* * *}$ & -1.450 & $-408.468^{* * *}$ & 0.000 & 0.000 \\
\hline & $(0.101)$ & $(5.488)$ & $(148.952)$ & (.) & $()$. \\
\hline \multirow[t]{2}{*}{$\log (\text { GDP pc. })^{2}$} & & 0.140 & $49.061^{* * *}$ & $-24.396^{* * *}$ & 0.000 \\
\hline & & $(0.327)$ & $(17.835)$ & $(8.981)$ & $()$. \\
\hline \multirow[t]{2}{*}{$\log (\text { GDP pc. })^{3}$} & & & $-1.960^{* * *}$ & $3.907^{* * *}$ & $-1.914^{* *}$ \\
\hline & & & $(0.712)$ & $(1.432)$ & $(0.721)$ \\
\hline \multirow[t]{2}{*}{$\log (\text { GDP pc. })^{4}$} & & & & $-0.176^{* * *}$ & $0.345^{* *}$ \\
\hline & & & & $(0.064)$ & $(0.129)$ \\
\hline \multirow[t]{2}{*}{$\log (\text { GDP pc. })^{5}$} & & & & & $-0.017^{* * *}$ \\
\hline & & & & & $(0.006)$ \\
\hline \multirow[t]{2}{*}{ P-log(GDP pc. $)^{1}$} & $-1139.631^{* * *}$ & $-1257.813^{* * *}$ & 0.000 & $-540.975^{* * *}$ & $-534.598^{* * *}$ \\
\hline & $(323.337)$ & $(418.749)$ & $()$. & $(139.004)$ & $(138.315)$ \\
\hline \multirow[t]{2}{*}{ P-log(GDP pc. $)^{2}$} & $243.307^{* * *}$ & $267.240^{* * *}$ & $-150.663^{* * *}$ & 0.000 & 0.000 \\
\hline & $(67.340)$ & $(86.242)$ & $(38.658)$ & (.) & $()$. \\
\hline \multirow[t]{2}{*}{ P-log (GDP pc. $)^{3}$} & $-22.938^{* * *}$ & $-25.090^{* * *}$ & $42.017^{* * *}$ & $21.068^{* * *}$ & $20.828^{* * *}$ \\
\hline & $(6.225)$ & $(7.888)$ & $(10.554)$ & $(5.188)$ & $(5.162)$ \\
\hline \multirow[t]{2}{*}{ P-log (GDP pc. $)^{4}$} & $0.807^{* * *}$ & $0.879^{* * *}$ & $-4.376^{* * *}$ & $-2.922^{* * *}$ & $-2.889^{* * *}$ \\
\hline & $(0.215)$ & $(0.270)$ & $(1.079)$ & $(0.707)$ & $(0.704)$ \\
\hline \multirow[t]{2}{*}{ P-log(GDP pc. $)^{5}$} & & & $0.161^{* * *}$ & $0.121^{* * *}$ & $0.120^{* * *}$ \\
\hline & & & $(0.039)$ & $(0.029)$ & $(0.029)$ \\
\hline Adjusted $R^{2}$ & 0.979 & 0.978 & 0.980 & 0.980 & 0.980 \\
\hline$A I C$ & -172.3 & -170.5 & -174.3 & -174.3 & -174.1 \\
\hline$B I C$ & -161.9 & -158.0 & -159.8 & -159.7 & -159.6 \\
\hline Observations & 59 & 59 & 59 & 59 & 59 \\
\hline
\end{tabular}

Notes: Paired region is India. Polynomial terms of the pair region is indicated with "P-" at the lower part of the table. Standard errors are in parentheses. Significance of the coefficients is labeled as ${ }^{*} p<0.10,{ }^{* *} p<0.05,{ }^{* * *} p<0.01$. 
Table 11: Pairwise Differenced ENNLS Estimations Other Asia

\begin{tabular}{|c|c|c|c|c|c|}
\hline & $(1)$ & $(2)$ & $(3)$ & $(4)$ & $(5)$ \\
\hline \multirow[t]{2}{*}{$\log (\text { GDP pc. })^{1}$} & $1.361^{* * *}$ & $17.217^{* * *}$ & 17.919 & 0.000 & $-637.544^{* * *}$ \\
\hline & $(0.101)$ & $(1.484)$ & $(39.326)$ & (.) & $(176.594)$ \\
\hline \multirow[t]{2}{*}{$\log (\text { GDP pc. })^{2}$} & & $-1.009^{* * *}$ & -1.097 & 2.722 & 0.000 \\
\hline & & $(0.094)$ & $(5.072)$ & $(2.458)$ & (.) \\
\hline \multirow[t]{2}{*}{$\log (\text { GDP pc. })^{3}$} & & & 0.004 & -0.355 & $20.868^{* * *}$ \\
\hline & & & $(0.218)$ & $(0.422)$ & $(5.715)$ \\
\hline \multirow[t]{2}{*}{$\log (\text { GDP pc. })^{4}$} & & & & 0.013 & $-2.657^{* * *}$ \\
\hline & & & & $(0.020)$ & $(0.726)$ \\
\hline \multirow[t]{2}{*}{$\log (\text { GDP pc. })^{5}$} & & & & & $0.101^{* * *}$ \\
\hline & & & & & $(0.028)$ \\
\hline \multirow[t]{2}{*}{ P-log (GDP pc. $)^{1}$} & $-3670.966^{* * *}$ & 0.000 & 0.000 & 0.000 & $-445.273^{* *}$ \\
\hline & $(422.080)$ & (.) & (.) & (.) & $(176.980)$ \\
\hline \multirow[t]{2}{*}{ P-log $(\text { GDP pc. })^{2}$} & $765.486^{* * *}$ & $13.802^{* * *}$ & $13.750^{* * *}$ & $13.840^{* * *}$ & 0.000 \\
\hline & $(88.038)$ & $(2.234)$ & $(2.322)$ & $(2.308)$ & $()$. \\
\hline \multirow[t]{2}{*}{ P-log (GDP pc. $)^{3}$} & $-70.713^{* * *}$ & $-2.415^{* * *}$ & $-2.405^{* * *}$ & $-2.422^{* * *}$ & $17.776^{* * *}$ \\
\hline & $(8.150)$ & $(0.404)$ & $(0.420)$ & $(0.417)$ & $(6.600)$ \\
\hline \multirow[t]{2}{*}{ P-log (GDP pc. $)^{4}$} & $2.443^{* * *}$ & $0.119^{* * *}$ & $0.118^{* * *}$ & $0.119^{* * *}$ & $-2.496^{* * *}$ \\
\hline & $(0.283)$ & $(0.020)$ & $(0.021)$ & $(0.021)$ & $(0.900)$ \\
\hline \multirow[t]{2}{*}{ P-log (GDP pc. $)^{5}$} & & & & & $0.105^{* * *}$ \\
\hline & & & & & $(0.037)$ \\
\hline Adjusted $R^{2}$ & 0.936 & 0.948 & 0.947 & 0.947 & 0.958 \\
\hline$A I C$ & -139.8 & -151.3 & -149.1 & -149.3 & -162.3 \\
\hline$B I C$ & -129.4 & -138.9 & -134.5 & -134.8 & -145.7 \\
\hline Observations & 59 & 59 & 59 & 59 & 59 \\
\hline
\end{tabular}

Notes: Paired region is India. Polynomial terms of the pair region is indicated with "P_" at the lower part of the table. Standard errors are in parentheses. Significance of the coefficients is labeled as ${ }^{*} p<0.10,{ }^{* *} p<0.05,{ }^{* * *} p<0.01$. 
Table 12: Pairwise Differenced ENNLS Estimations Western Europe

\begin{tabular}{|c|c|c|c|c|c|}
\hline & $(1)$ & $(2)$ & $(3)$ & $(4)$ & $(5)$ \\
\hline \multirow[t]{2}{*}{$\overline{\log (\text { GDP pc. })^{1}}$} & $0.831^{* * *}$ & $7.741^{* * *}$ & $50.799^{* * *}$ & 0.000 & 169.070 \\
\hline & $(0.058)$ & $(1.800)$ & $(13.809)$ & $()$. & $(103.354)$ \\
\hline \multirow[t]{2}{*}{$\log (\text { GDP pc. })^{2}$} & & $-0.396^{* * *}$ & $-5.302^{* * *}$ & $2.920^{* * *}$ & 0.000 \\
\hline & & $(0.104)$ & $(1.480)$ & $(0.768)$ & $()$. \\
\hline \multirow[t]{2}{*}{$\log (\text { GDP pc. })^{3}$} & & & $0.186^{* * *}$ & $-0.405^{* * *}$ & -3.739 \\
\hline & & & $(0.053)$ & $(0.110)$ & $(2.424)$ \\
\hline \multirow[t]{2}{*}{$\log (\text { GDP pc. })^{4}$} & & & & $0.016^{* * *}$ & 0.394 \\
\hline & & & & $(0.004)$ & $(0.262)$ \\
\hline \multirow[t]{2}{*}{$\log (\text { GDP pc. })^{5}$} & & & & & -0.012 \\
\hline & & & & & $(0.008)$ \\
\hline \multirow[t]{2}{*}{ P-log (GDP pc. $)^{1}$} & $0.958^{* * *}$ & $7.914^{* * *}$ & $0.499^{* * *}$ & $0.504^{* * *}$ & $0.477^{* *}$ \\
\hline & $(0.071)$ & $(2.079)$ & $(0.181)$ & $(0.181)$ & $(0.180)$ \\
\hline \multirow[t]{2}{*}{ P-log (GDP pc. $)^{2}$} & & $-0.385^{* * *}$ & & & \\
\hline & & $(0.110)$ & & & \\
\hline \multicolumn{6}{|l|}{ P-log (GDP pc. $)^{3}$} \\
\hline \multicolumn{6}{|l|}{ P-log (GDP pc. $)^{4}$} \\
\hline \multicolumn{6}{|l|}{ P-log(GDP pc. $)^{5}$} \\
\hline Adjusted $R^{2}$ & 0.799 & 0.831 & 0.832 & 0.831 & 0.835 \\
\hline$A I C$ & -243.5 & -253.0 & -253.8 & -253.4 & -255.8 \\
\hline$B I C$ & -237.2 & -242.6 & -243.4 & -243.0 & -245.4 \\
\hline Observations & 59 & 59 & 59 & 59 & 59 \\
\hline
\end{tabular}

Notes: Paired region is Western Offshoots. Polynomial terms of the pair region is indicated with "P-" at the lower part of the table. Standard errors are in parentheses. Significance of the coefficients is labeled as ${ }^{*} p<0.10,{ }^{* *} p<0.05,{ }^{* * *} p<0.01$. 
Table 13: Cointegration tests for other regions

\begin{tabular}{|c|c|c|c|c|c|}
\hline & \multicolumn{2}{|c|}{ Test Statistics } & \multicolumn{3}{|c|}{ Critical Values } \\
\hline & 1 Stage & 2 Stage & $90 \%$ & $95 \%$ & $99 \%$ \\
\hline & \multicolumn{5}{|c|}{ Africa (paired to: Latin America) } \\
\hline \multicolumn{6}{|l|}{ H0: Cointegration } \\
\hline KPSS & 0.265 & 0.690 & 0.140 & 0.191 & 0.348 \\
\hline Sub-sample KPSS & 0.617 & 0.530 & 3.741 & 4.220 & \\
\hline \multicolumn{6}{|l|}{ H0: No cointegration } \\
\hline \multirow[t]{2}{*}{ Variance ratio test } & 23.630 & 22.351 & 39.676 & 47.702 & 63.828 \\
\hline & \multicolumn{5}{|c|}{ Eastern Europe - Former USSR } \\
\hline \multicolumn{6}{|l|}{ H0: Cointegration } \\
\hline KPSS & 0.436 & 0.166 & 0.161 & 0.219 & 0.384 \\
\hline Sub-sample KPSS & 2.361 & 0.612 & 3.588 & 4.081 & \\
\hline \multicolumn{6}{|l|}{ H0: No cointegration } \\
\hline \multirow[t]{2}{*}{ Variance ratio test } & 14.634 & 14.985 & 33.850 & 40.903 & 55.800 \\
\hline & \multicolumn{5}{|c|}{ India - Latin America } \\
\hline \multicolumn{6}{|l|}{ H0: Cointegration } \\
\hline KPSS & 0.294 & 0.527 & 0.137 & 0.186 & 0.339 \\
\hline Sub-sample KPSS & 0.733 & 0.896 & 3.276 & 3.797 & \\
\hline \multicolumn{6}{|l|}{ H0: No cointegration } \\
\hline \multirow[t]{2}{*}{ Variance ratio test } & 31.092 & 36.119 & 41.457 & 49.663 & 66.696 \\
\hline & \multicolumn{5}{|c|}{ Other Asia (paired to: India) } \\
\hline \multicolumn{6}{|l|}{ H0: Cointegration } \\
\hline KPSS & 0.158 & 0.058 & 0.110 & 0.154 & 0.306 \\
\hline Sub-sample KPSS & 1.614 & 0.480 & 3.741 & 4.220 & \\
\hline \multicolumn{6}{|l|}{ H0: No cointegration } \\
\hline \multirow[t]{2}{*}{ Variance ratio test } & 15.660 & 18.592 & 74.506 & 85.437 & 104.851 \\
\hline & \multicolumn{5}{|c|}{ Western Europe - Western Offshoots } \\
\hline \multicolumn{6}{|l|}{ H0: Cointegration } \\
\hline KPSS & 0.074 & 0.090 & 0.137 & 0.193 & 0.342 \\
\hline Sub-sample KPSS & 0.964 & 1.076 & 3.484 & 3.983 & \\
\hline \multicolumn{6}{|l|}{ H0: No cointegration } \\
\hline Variance ratio test & 31.006 & 31.357 & 45.521 & 54.064 & 73.813 \\
\hline
\end{tabular}

Note: In case of "Eastern Europe - Former USSR", "India - Latin America", and "Western Europe - Western Offshoots", the pairs are best pairs to each other, leading to the same cointegration test statistics for each of the pairs. In case of Africa and Other Asia, the pairs have different best pairs. 
Figure 8: Pairwise Differencing Estimations for China with Alternative Best Pairs

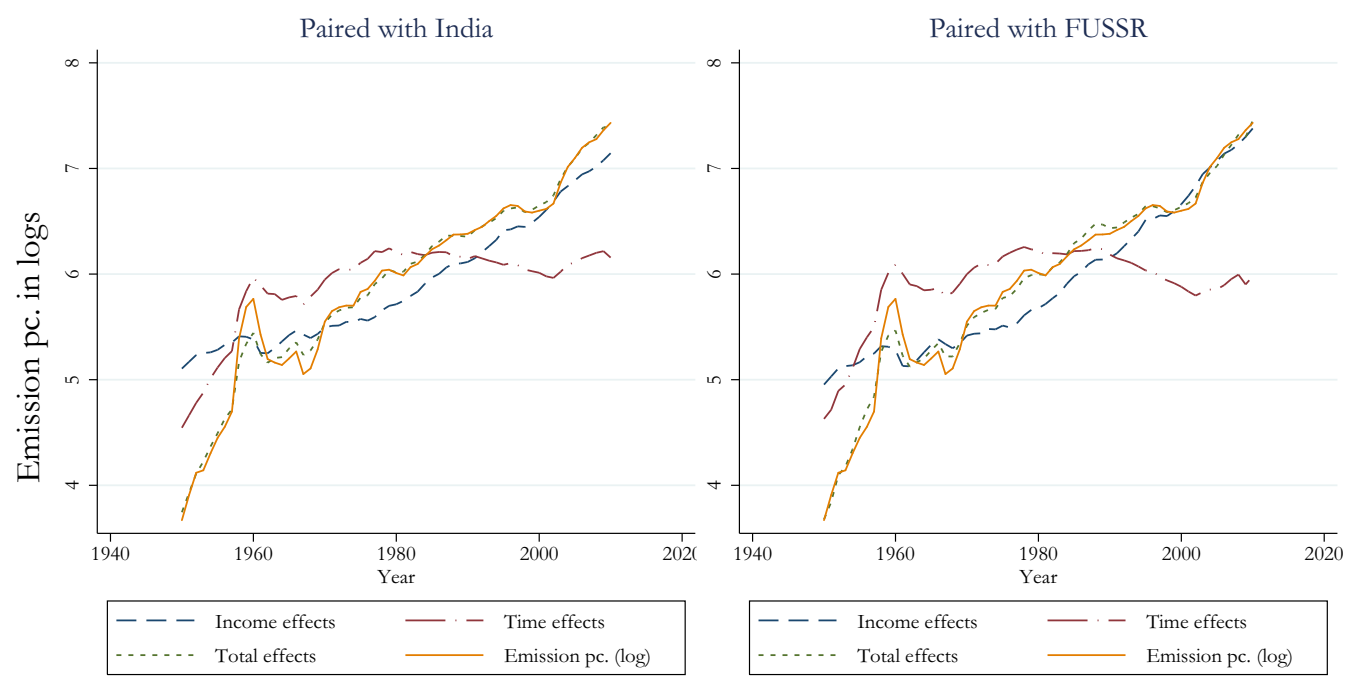

Explanation: This figure shows the estimated effects of the EN-NLS estimation for China when coupled with India and Former USSR. All series are in logarithms. Levels of the estimated effects are normalized such that the means are equal to the mean of observed emission series (in logs). 